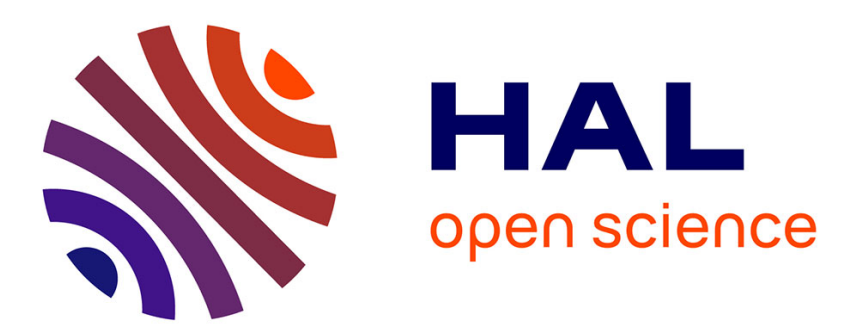

\title{
Photocross-Linked Peptide-Protein Complexes Analysis: A Comparative Study of CID and ETD Fragmentation Modes
}

\author{
Séverine Clavier, Gérard Bolbach, Emmanuelle Sachon
}

\section{To cite this version:}

Séverine Clavier, Gérard Bolbach, Emmanuelle Sachon. Photocross-Linked Peptide-Protein Complexes Analysis: A Comparative Study of CID and ETD Fragmentation Modes. Journal of The American Society for Mass Spectrometry, 2015, 26 (6), pp.1014-1026. 10.1007/s13361-015-1095-0 . hal-01140193

\author{
HAL Id: hal-01140193 \\ https://hal.science/hal-01140193
}

Submitted on 29 Apr 2015

HAL is a multi-disciplinary open access archive for the deposit and dissemination of scientific research documents, whether they are published or not. The documents may come from teaching and research institutions in France or abroad, or from public or private research centers.
L'archive ouverte pluridisciplinaire HAL, est destinée au dépôt et à la diffusion de documents scientifiques de niveau recherche, publiés ou non, émanant des établissements d'enseignement et de recherche français ou étrangers, des laboratoires publics ou privés. 
analysis: A comparative study of CID and ETD

\section{fragmentation modes}

Clavier S., Bolbach, G., Sachon, E.

Address reprint requests to Emmanuelle Sachon, Université P. et M. Curie, 7-9 quai saint Bernard, Bât. A, case courier 41, 75005 Paris, France. Telephone: +33144273234 , fax: +33144272291 , e-mail emmanuelle.sachon@upmc.fr 


\section{Abstract}

Protein-protein interactions are among the keys to organizing cellular processes in space and time. One of the only direct ways to identify such interactions in their cellular environment is to covalently bond the interacting partners to fix the interaction. Photocross-linking in living cells is thus a very promising technique. The feasibility of in cellulo photocross-linking reactions has been shown and mass spectrometry is a tool of choice to analyze photocross-linked proteins. However, the interpretation of the MS and MS/MS spectra of photocross-linked peptides remains one of the most important bottlenecks of the method and still limits its potential for large-scale applications (interactomics). Fundamental studies are still necessary to understand and characterize the fragmentation behavior of photocross-linked peptides. Here, we report the successful identification of the interaction sites in a well-characterized model of in vitro interaction between a protein and a peptide. We describe in details the fragmentation pattern of these photocross-linked species in order to identify trends that could be generalized. In particular, we compare CID and ETD fragmentation modes (and HCD in a lesser extent), demonstrating the complementarity of both methods and the advantage of ETD for the analysis of photocross-linked species. The information should help further developing dedicated softwares to properly score MS/MS spectra of photocross-linked species.

\section{Introduction}

The relative maturation of the proteomics technologies for protein identification led to the emergence of ever more complex biological questions in order to understand the dynamics of living organisms. Among these, one crucial point is the elucidation of how these proteins interact in vivo with each other (interactome). Classical bottom-up proteomics is not well suited to determine these interactions which are, by nature, fragile and transient. The developments of the so-called native mass spectrometry could be a breakthrough, but the technologies are for now not ready for largescale applications. Cross-linking has been developed as a way to use bottom-up proteomics for interaction studies. The elegant principle is based on the use of a cross-linker that can covalently fix the interaction between proteins in order to preserve them all along the sample preparation and up 
to the MS and MS/MS analysis. In chemical cross-linking, the cross-linker is a small molecule whose extremities are chemically reactive and tailored to target chosen amino acids, like lysine or cysteine residues [1]. Chemical cross-linking coupled to mass spectrometry has already been used as lowresolution protein structure determination technique [1]. Solvent accessibility of residues can be directly checked, similarly to the H/D exchange. However, chemical cross-linking has several limitations such as i) the cross-linker selectivity towards specific residues which limits the interactions that can be preserved; ii) the low yield of cross-linking reaction; iii) the rapid hydrolysis of cross-linker reactive groups in solution (in vitro or in cellulo); iv) the uncontrolled reactivity of the cross-linker in time and space; (v) the limited ability of some cross-linker to pass the cell membrane for in cellulo applications. Therefore, it is often used in vitro but rarely found in the literature for in cellulo or in vivo experiments except for a few examples using formaldehyde, a non selective and also toxic reagent, resulting in extensive and complex cross-linking [2]. To overcome these issues, photoinduced cross-linking has been developed in chemical biology by using photo-reactive groups which can now be routinely incorporated into the proteins either chemically or metabolically $[3,4]$ and then used in the native environment [5]. Scheme A1 (electronic Supplemental Material) shows three commonly used photoprobes. However, unlike chemical cross-linking which targets specific residues, photocross-linking can involve any $\mathrm{C}-\mathrm{H}$ bond of any amino acids which drastically increases the number of possible photocross-linked products in a reaction mixture and gives the opportunity to get information about the covalent link at the atomic level. Therefore, the data interpretation still remains very challenging in a classical database search strategy, because it requires considering the possibility of any link between all the potential peptides, leading to an explosion in search space and in false positive identifications.

The average molecular weight of tryptic photocross-linked peptides corresponds to the sum of the two digested peptides linked and is thus typically $>2000 \mathrm{u}$. This high mass and thus the large number of degrees of freedom is not in favor of an effective fragmentation by classical CID through low energy collision. In addition, fragmentation spectra obtained for a precursor ion where two peptides 
are covalently linked are much more complex as these spectra contain fragmentation patterns of both peptides, as well as possible internal fragmentations if the covalent bond formed remains intact. This is common to all cross-linking strategies and requires dedicated softwares taking into account special features of cross-linked peptides such as their fragmentation pathways. StavroX is, to our knowledge, the first software able to deal with MS/MS spectra of photocross-linked species [6]. $\mathrm{CID}$, the most commonly used fragmentation method for tandem mass spectrometry (MS/MS) analyses of peptides and proteins, relies on activation by energetic collisions of the protonated analytes with a neutral gas. In high-energy CID (keV), the collision gas pressure is low enough $\left(\leq 10^{-7}\right.$ Torr) that only a few collisions can occur, while in low-energy CID (eV) a collision gas pressure of $10^{-3}$ Torr allows multiple collisions with the ions to be fragmented, which increases internal energy and yields extensive dissociation. CID typically induces fragmentation of the amide bonds $\mathrm{CO}-\mathrm{NH}$ of the peptides generating the $b$ - and $y$ - fragment ions series $[7,8]$.

In general, CID is more effective for small, low-charged peptides [9]. Therefore, one can suppose that with CID fragmentation, the amount of energy required to fragment large cross-linked peptide ions would be high due to the isomerization of the internal energy over a larger number of degrees of freedom.

Electron-transfer dissociation (ETD), developed by Hunt et al. [10], has also shown much promise for the sequencing of peptides and proteins. Compared to CID, ETD is described as more favorable to analyze large peptides, proteins, and labile post-translational modifications (PTMs) [11-14]. This gasphase radical process leads to a rapid homolytic fragmentation mainly at the site where the originally formed radical was trapped [15] thereby promoting $\mathrm{N}-\mathrm{C} \alpha$ fragmentation that yield c- and $\mathrm{z}^{\bullet}$-type fragment ions, leaving side-chains as well as PTMs intact.

In this study, we performed an advanced evaluation of photocross-linked peptides CID and ETD fragmentation spectra obtained for a model interacting system composed of BSA protein and (R/W $)_{9}$ cell penetrating peptide bearing here a benzophenone $(\mathrm{Bp})$ photoactivable group $[16,17]$. We used two different mass spectrometer instruments and four activation modes for the study of photocross- 
linked peptides fragmentation. We applied either high-energy CID-based fragmentation (keV) using a MALDI-TOF/TOF instrument or low energy CID (eV), HCD (Higher-energy Collisional Dissociation) (eV range) and ETD fragmentation using a nanoLC ESI-LTQ/Orbitrap system enabling rapid cycling between alternate CID and ETD or CID and HCD fragmentations on the same set of precursor ions in a data-dependent manner. This study allowed us to assess the suitability of the different fragmentation modes for the analysis of photocross-linked peptides. ETD revealed to be particularly adapted for the determination of the residues involved in the photocross-linking reaction. We hope that such a study will help future developments to implement new scoring methods and improve the identification and characterization of photocross-linked peptides by mass spectrometry in order to investigate later biologically relevant interacting systems in cellulo (interactomic).

Experimental

Peptide synthesis: The CPP biotin $\left(\mathrm{O}_{2}\right)-\mathrm{G}_{5}-\mathrm{K}(\mathrm{Bp})-\mathrm{RRWWRRWRR}$ (photo $(\mathrm{R} / \mathrm{W})_{9}$ ) was synthesized in both deuterated and non deuterated versions, incorporating or not 2 deuterium atoms to each of the 5 glycines in the spacer arm by R. Marquant from our laboratory. The peptide synthesis was realized as previously published in ref [18] with some modifications. Briefly, the biologically active $(R / W)_{9}$ peptide sequence $\mathrm{NH}_{2}$-RRWWRRWRR was first synthesized with a peptide synthesizer (Applied Biosystems, Darmstadt, Germany, model 433A) using a solid phase butyloxicarbonyl (Boc) chemistry in the $0.1 \mathrm{mmol}$ scale, starting from a p-methylbenzhydrylamine resin (MBHA resin). Standard protocols were used, with DCC/HOBt activation (10 eq. excess for standard Boc amino acids). After the removal of the last N $\alpha$-Boc protecting group, the synthesis was manually completed by adding the protected Lysine residue (Boc-Lys(Fmoc)-OH). The resin was dried in vacuo and separated into two batches for the manual addition of the 5 Boc-Gly-OH either bideuterated or not followed by the addition of the biotinyl sulfone. The Lysine(Boc-Arg(Tosyl)-OH) and tryptophane (Boc-Trp(Formyl)$\mathrm{OH}$ ) residues were then deprotected using $20 \%$ piperidin. Then, the carboxybenzophenone was coupled to the lateral chain of the deprotected lysine residue. Finally, both peptidyl-MBHA-resins were treated with liquid $\mathrm{HF}$ at $0^{\circ} \mathrm{C}(2 \mathrm{~h} 30)$ under stirring, in the presence of anisole and 
dimethylsulfide. After evaporation of HF and of the solvents in vacuo, the resins were washed three times with $\mathrm{Et}_{2} \mathrm{O}$ and then subsequently extracted three times with $10 \% \mathrm{AcOH}$. Lyophilization of the extracts gave crude peptides, which were purified by HPLC and purity was checked by UV (> $95 \%$ ) and by MALDI-TOF MS.

Photocross-linking reaction: $100 \mu \mathrm{L}$ of a solution of $10 \mu \mathrm{M}$ BSA (Sigma, Saint Louis, Missouri, USA) and $10 \mu \mathrm{M}$ of both the deuterated and the non-deuterated form of photo(R/W) $)_{9}$ in $\mathrm{NH}_{4} \mathrm{HCO}_{3} 50 \mathrm{mM}$ and $\mathrm{NaCl} 150 \mathrm{mM}$ to mimic physiological conditions was prepared and placed into two Eppendorf tubes. One of the tube was wrapped into aluminum foil (negative control) while the other was kept opened. These tubes were placed in a water/ice bath to avoid heating since the light emitted by the UV lamp is absorbed by the sample and introduced in the photoirradiation chamber at a distance of about $5 \mathrm{~cm}$ of the lamp (HPR 125W-mercury lamp, Philips) and irradiated for $30 \mathrm{~min}$.

Enzymatic trypsin digestion: After irradiation, the photocross-linking reaction mixtures were submitted to in-solution trypsin digestion. Disulfide bridges were reduced ( $5 \mathrm{mM}$ dithiothreitol, 15 $\min , 50^{\circ} \mathrm{C}$ ) and cysteines were alkylated $(20 \mathrm{mM}$ iodoacetamide, $30 \mathrm{~min}$, room temperature in the dark). Trypsin (Promega, gold, mass spectrometry grade) digestion was conducted at $37^{\circ} \mathrm{C}$ overnight (1:30 (w:w) protease-to-protein ratio).

Biotinylated photocross-linked peptides affinity purification: A volume of tryptic digest corresponding to $80 \mathrm{pmol}$ of photo(R/W) $)_{9} \mathrm{CPP}$ was incubated with $200 \mu \mathrm{g}$ of streptavidin magnetic beads (Dynabeads M280 streptavidin coated magnetic beads from Invitrogen, Carlsbad, New Mexico, USA) for $60 \mathrm{~min}$ at RT under gentle stirring. Beads were conditioned before use and washed after incubation [19]. Peptides were eluted from the beads with $5 \mu \mathrm{L}$ of $0.1 \mathrm{M}$ hydrochloric acid $(\mathrm{HCl})$ under gentle stirring (30 $\mathrm{min})$.

MS and MS/MS analysis of photocross-linked peptides: 
MALDI-TOF/TOF: Spectra were obtained with an AB4700 Proteomics Analyzer mass spectrometer (AB Sciex) in positive ions reflector mode and delayed extraction. CHCA (Sigma) was used as the matrix and solubilized at $5 \mathrm{mg} / \mathrm{mL}$ in $1 / 1 \mathrm{ACN} / 0.1 \%$ trifluoroacetic acid (TFA). $0.5 \mu \mathrm{L}$ of the biotinylated photocross-linked peptides solution eluted from the beads was mixed with $0.5 \mu \mathrm{L}$ of matrix and deposited on the MALDI plate. For MALDI-TOF spectra a total of 10,000 laser shots were acquired in the $\mathrm{m} / \mathrm{z}$ range 500-5000. MALDI-TOF/TOF spectra were acquired simultaneously for the two peaks of doublets by centering the selection window on the average $m / z$ value with a low resolution $R=30$. The metastable suppressor ion mode was first turned off for a few shots to check if both ions were correctly selected and then turned on for the rest of the MS/MS acquisition. On average, 30,000 laser shots were accumulated for each MS/MS spectrum.

NanoLC-ESI-Orbitrap: The analysis of the photocross-linked peptides was performed using an Ultimate 3000 Nano-HPLC system (Dionex) coupled with a LTQ-Orbitrap-XL mass spectrometer (Thermo Scientific). The biotinylated photocross-linked peptides solution eluted from the beads was diluted by two in deionized $\mathrm{H}_{2} \mathrm{O}$ and transferred into a HPLC vial. $5 \mu \mathrm{L}$ were injected and concentrated on a trapping column $\left(C_{18}, 300 \mu \mathrm{m} \times 5 \mathrm{~mm}, 5 \mu \mathrm{m}, 100 \AA \AA\right.$, Dionex) with $99 \%$ solvent A (2 $\%$ acetonitrile $(\mathrm{ACN}), 0.1 \%$ formic acid) at a flow rate of $20 \mu \mathrm{L} / \mathrm{min}$ for $10 \mathrm{~min}$. The peptides were separated on a column $\left(C_{18}, 75 \mu \mathrm{m} \times 150 \mathrm{~mm}, 3 \mu \mathrm{m}, 100 \AA\right.$, Dionex) equilibrated with $98 \%$ solvent A. Peptides were separated at a flow rate of $300 \mathrm{~nL} / \mathrm{min}$ using the following gradient: $0-90 \mathrm{~min} 2-40$ \% solvent B (98 \% ACN, $0.1 \%$ formic acid), 90-93 min 40-60\% solvent B, 93-110 min $60 \%$ solvent B. The LTQ-Orbitrap mass spectrometer was outfitted with a nano ESI interface. Electrospray emitters were $360 / 20 \mu$ o.d. $\times 10 \mu$ i.d. fused-silica tips (PicoTip Emitter, standard Coated SilicaTip, New Objective). The heated capillary temperature and spray voltage were $200{ }^{\circ} \mathrm{C}$ and $1.5 \mathrm{kV}$, respectively. The LTQ Orbitrap XL was operated in positive ion and data dependent acquisition mode. Orbitrap full scan spectra (automated gain control (AGC) $2.10^{5}$ ) were collected in the range $\mathrm{m} / \mathrm{z} 300-2000$ at a resolution of 30,000 in the profile mode followed by sequential ion trap CID and ETD MS/MS spectra of the three most intense ions (AGC target : 2500, isolation width CID $4.0 \mathrm{~m} / \mathrm{z}$, ETD $2.0 \mathrm{~m} / \mathrm{z}$, ETD 
reagent ion AGC target $3.10^{5}$, ETD reaction time $100 \mathrm{~ms}$ ) using the Masstag option corresponding to the mass difference of $10.06 \mathrm{u}$. and with various charge states $(\Delta \mathrm{m} / \mathrm{z} 10.06 ; 5.03 ; 3.35 ; 2.52 ; 2.01$; 1.68; partner intensity tolerance $70-100 \%$ and choice of both partners fragmentation). For ETD fragmentation a supplemental activation (SA) of $20 \%$ was used.

\section{Results and Discussion}

We previously characterized the interaction between the BSA protein and a modified version of the cell-penetrating peptide (CPP), namely $(\mathrm{R} / \mathrm{W})_{9}$ containing a Lys residue at the $\mathrm{N}$-terminus to allow chemical cross-linking [16]. In the present study we developed a general workflow using photocrosslinking to characterize interacting systems. We validated this technique using the interacting model system $(\mathrm{R} / \mathrm{W})_{9} / \mathrm{BSA}$ by designing a photoactivable CPP analog of $(\mathrm{R} / \mathrm{W})_{9}$, namely photo(R/W $)_{9}$, which has the following sequence: biotin $(\mathrm{O})_{2}-\mathrm{G}_{5}-\mathrm{K}(\mathrm{Bp}) \mathrm{RRWWRRWRR}$. The $\varepsilon \mathrm{NH}_{2}$ of the lateral chain of the Lys residue is substituted with a benzophenone $(\mathrm{Bp})$ moiety. The biotin added at the $\mathrm{N}$-terminus allows purification of the photocross-linked species. This biotin is oxidized to biotin sulfone (biot $\left(\mathrm{O}_{2}\right)$, to avoid further oxidation during the sample preparation which would dilute the MS signal of the photocross-linked species (more species with lower intensity each). The photo(R/W) ${ }_{9}$ peptide was synthesized in heavy and light forms thanks to the presence of the 5 Gly residues that can be deuterated. Performing the photocross-linking reaction with a 1:1 mixture of the heavy and light photo(R/W $)_{9}$ should allow an easier MS1 determination of the ions corresponding to photocrosslinked species which should appear as 1:1 doublets separated by a fixed 10.06/z difference.

The Bp moiety, present on the photo $(\mathrm{R} / \mathrm{W})_{9}$, once activated via UV-irradiation at $365 \mathrm{~nm}$ (creation of a biradical), can lead to the formation of a covalent bond at any of the $\mathrm{C}-\mathrm{H}$ or heteroatom- $\mathrm{H}$ bonds of the interacting partner, as long as these atoms are sufficiently close to the photoprobe, by a well known and controlled reaction as shown in Figure 1. However, the knowledge of the cross-linking site and residue remains difficult to extract from the list of branched peptide fragments even with known interacting partners in vitro. 
Fig. 1

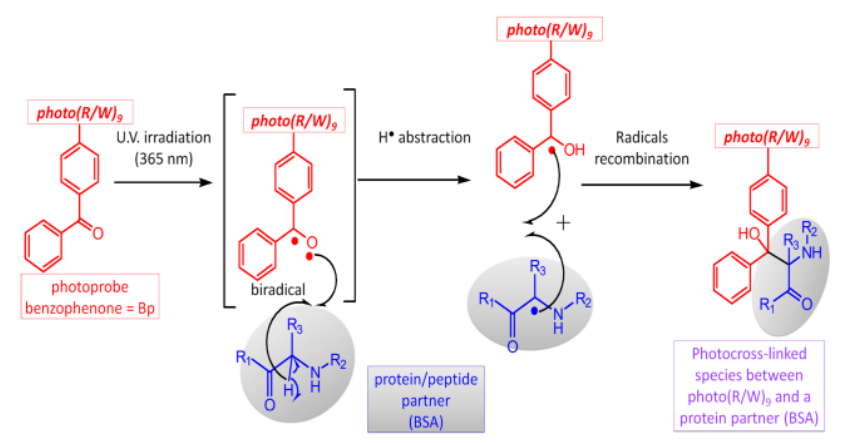

After UV-irradiation of the photo $(\mathrm{R} / \mathrm{W})_{9} / \mathrm{BSA}$ partners in the conditions described above, complexes obtained were trypsin digested and the biotinylated species - corresponding to the unreacted photo $(\mathrm{R} / \mathrm{W})_{9}$ or cross-linked photo $(\mathrm{R} / \mathrm{W})_{9}$ with $\mathrm{BSA}$ peptides - were purified using streptavidin coated magnetic beads. As shown on the MALDI-TOF spectrum presented in Figure $2 \mathrm{a}$, this purification step was very efficient and led to the specific observation of only 1:1 doublets separated by $10.06 / z$ mass units.

Fig. 2 


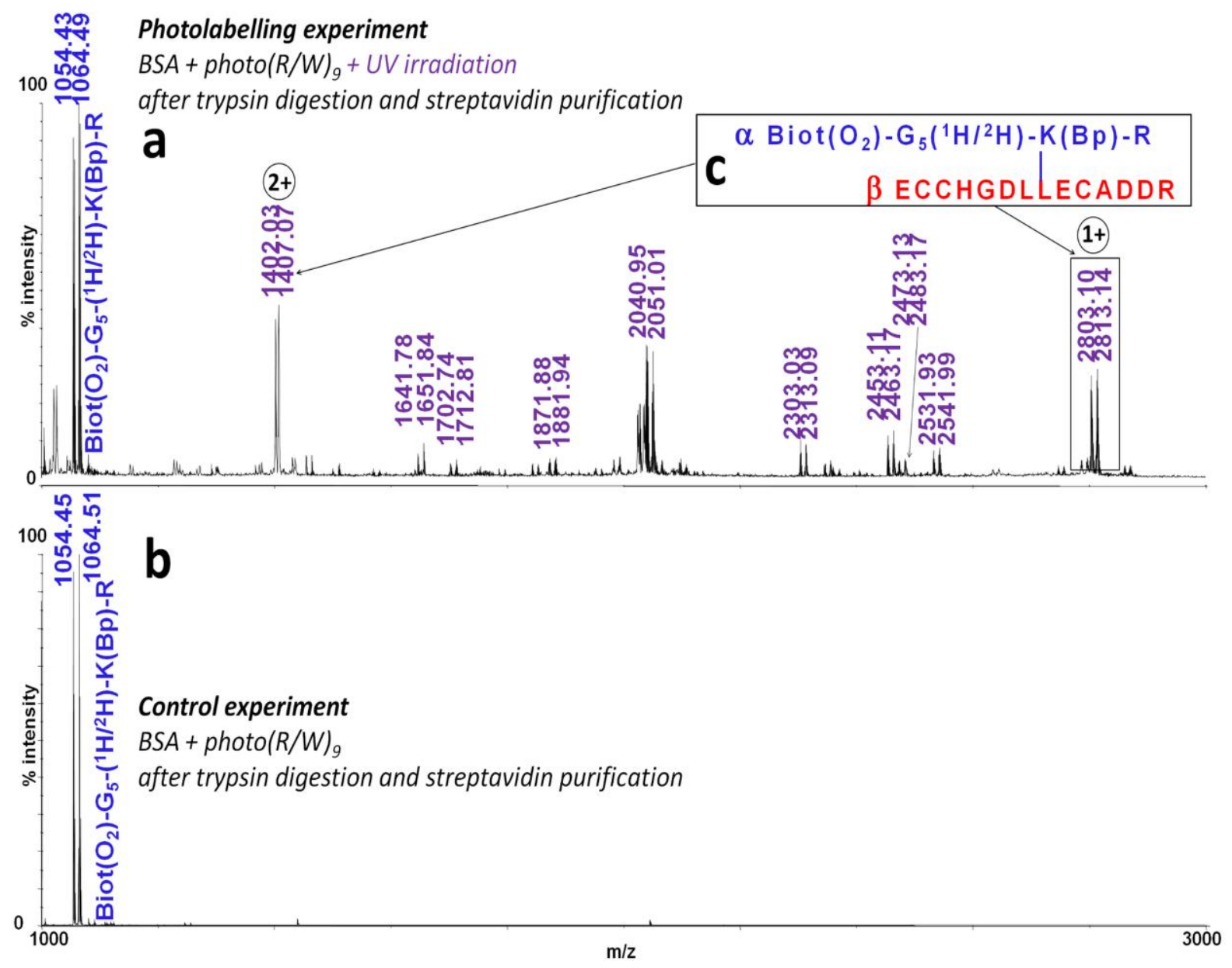

The presence of these doublets shows that the processes (photocross-linking reaction, digestion, purification, analysis) are those expected and without artifacts for both forms of photo $(\mathrm{R} / \mathrm{W})_{9}$. The base peak at $\mathrm{m} / \mathrm{z}$ 1054-1064 (doublet) corresponds to the photo(R/W) ${ }_{9}$ entirely digested by trypsin (namely photo(R/W) ${ }_{9}$ pept(1-8): biotin $(O)_{2}-G G G G G-K(B p)-R$ ). The negative control (Figure 2b) , corresponding to the same sample without photoirradiation, only contained this doublet, indicating that all the ions with higher $\mathrm{m} / \mathrm{z}$ in Figure 1 are specific of the photocross-linking reaction. The prevalence of unreacted photo $(\mathrm{R} / \mathrm{W})_{9}$ after photocross-linking revealed the incomplete reaction and the efficient trypsin digestion of photo $(\mathrm{R} / \mathrm{W})_{9}$ since no partial digestion products were observed. However, we can assume that the photocross-linking reaction occurred with a relatively high yield, taking into account the high number of different photocross-linked peptide products with a contribution of more than 10 different species that dilute the signal in the MS spectrum (Figure 2). 
This result is in good agreement with the high yield of photocross-linking described in the literature using the Bp photoprobe [20].

The $\mathrm{m} / \mathrm{z}$ of the potential photocross-linked peptides resulting from the interaction between photo(R/W $)_{9}$ and $B S A$ followed by trypsin digestion can be easily computed. For this simple model system, it was possible to identify most of the photocross-linking product ions of the MALDI-TOF MS spectrum (Figure 2 ) by manually comparing theoretical and measured $\mathrm{m} / \mathrm{z}$ of the doublets (Table 1 ).

Table 1

\begin{tabular}{|c|c|c|c|c|}
\hline Exp. m/2 & Theo. $\mathrm{m} / \mathrm{z}$ & $\begin{array}{l}\Delta \text { mass } \\
\text { (ppm) }\end{array}$ & $\begin{array}{l}\text { photo(R/W)g } \\
\text { tryptic pept. } \\
\text { a sequence }\end{array}$ & $\begin{array}{c}\text { BSA tryptic pept. } \\
\beta \text { sequence }\end{array}$ \\
\hline $1054.44-1064.49$ & $1054.45-1064.52$ & 19 & pep 1-8 & $\cdot$ \\
\hline $1402.54-1407.57(2+)$ & $1402.05-1407.09(2+)$ & 14 & pep 1-8 & ${ }^{267}{ }^{E C C H G D L L E C A D D R}{ }^{280}$ \\
\hline $1641.78-1651.84$ & 1641.81-1651.87 & 18 & pep 1-9 & ${ }^{456}$ VGTR $^{459}$ \\
\hline $1702.74-1712.81$ & $1702.77-1712.84$ & 17 & pep 1-8 & ${ }^{205 \mid E T M R}{ }^{209}$ \\
\hline 1871.88-1881.94 & $1871.87-1881.93$ & 5 & pep 1-8 & ${ }^{562}$ ATEEQLK568 \\
\hline $2040.95-2051.01$ & $2040.98-2051.05$ & 20 & pep 1-8 & ${ }^{29}$ SEIAHRFK ${ }^{36}$ \\
\hline $2303.03-2313.09$ & $2313.06-2313.13$ & 17 & pep 1-8 & ${ }^{35}$ FKDLGEEHFK ${ }^{44}$ \\
\hline $2453.11-2463.17$ & $2453.13-2463.20$ & 12 & pep 1-8 & ${ }^{569}$ TVMENFVAFVDK $^{580}$ \\
\hline $2473.10-2483.17$ & $2473.13-2483.20$ & 12 & pep $1-8$ & ${ }^{89}$ SLHTLFGDELCK ${ }^{100}$ \\
\hline $2531.93-2541.99$ & $2531.96-2542.03$ & 16 & pep 1-8 & ${ }^{106}$ ETYGDMADCCEK $^{117}$ \\
\hline $2803.08-2813.14$ & $2803.10-2813.17$ & 10 & pep 1-8 & ${ }^{267}$ ECCHGDLLECADDR $^{280}$ \\
\hline
\end{tabular}

However, the localization of the cross-linked residues requires complete series of relevant MS2 fragments and time consuming manual fragments interpretation. In a broader context, fragmentation will obviously be necessary for identification of unknown partners in more complex interacting systems (in cellulo). All the enriched (biotin/streptavidin affinity purification) photocrosslinked peptide sequences identified in this study (Table 1) were submitted to MS2. We applied either high-energy CID-based fragmentation (keV) using a MALDI-TOF/TOF instrument or low-energy CID (eV) and ETD fragmentation using an ESI-LTQ Orbitrap XL system. HCD (eV range) was also performed and evaluated for different photocross-linked peptides. This fragmentation type did not generate reproducibly informative spectra for the various photocross-linked peptides probably due to the low amount of material and mainly to the energy function of the HCD cell on the LTQ-Orbitrap -XL instrument which is not optimized. Spectra appeared extremely noisy with no valuable sequence 
information. However, when sensitivity was not a limiting factor, HCD could lead to informative

\section{MS2 spectra.}

The study was conducted on all photocross-linked peptides and for the sake of simplicity, the comparison of the different fragmentation types (low- and high-energy CID, ETD and in a lesser extent $H C D$ ) will be illustrated on doublet precursor ion identified as the tryptic BSA peptide containing 3 carbamidomethylcystein residues : ${ }^{267}$ ECCHGDLLECADDR $^{280}$, covalently linked to the photo(R/W) ${ }_{2}$ pept(1-8) (Figure $2 \mathrm{c}$ ). This doublet ion has one of the highest $\mathrm{m} / \mathrm{z}$ in the MALDI-TOF spectrum (Figure 2a) and is relatively abundant, existing as both singly and doubly protonated ions (doublets at $\mathrm{m} / \mathrm{z} 2803-2813$ and 1402-1407, respectively). Other examples are presented in the Supplementary Information.

The nomenclature that will be used to describe the CID and ETD fragment ions of both peptides covalently linked in the photocross-linked species, namely sequence $\alpha$ and $\beta$ for the photo(R/W $)_{9}$ pept(1-8) and the BSA trypsic peptide respectively, is presented in Figure 3. Unlinked y- and b- or cand $z$ - fragment ions correspond to linear peptides arising from the photo(R/W) 9 pept(1-8) (sequence $\alpha$, in blue) or from the BSA peptide (sequence $\beta$, in red). Interlinked $y$ - and b- or c- and z-fragment ions contain residues from both sequences $\alpha$ and $\beta$ covalently linked by the Bp moiety with a fragmentation that occurred along the $\alpha$ or $\beta$ sequence (in purple). Fragmentation occurring at a C-C bond was also observed and named $\mathrm{C}-\mathrm{C} \alpha$ or $\mathrm{C}-\mathrm{C} \beta$ depending on the fragment ion that is observed.

Fig. 3 


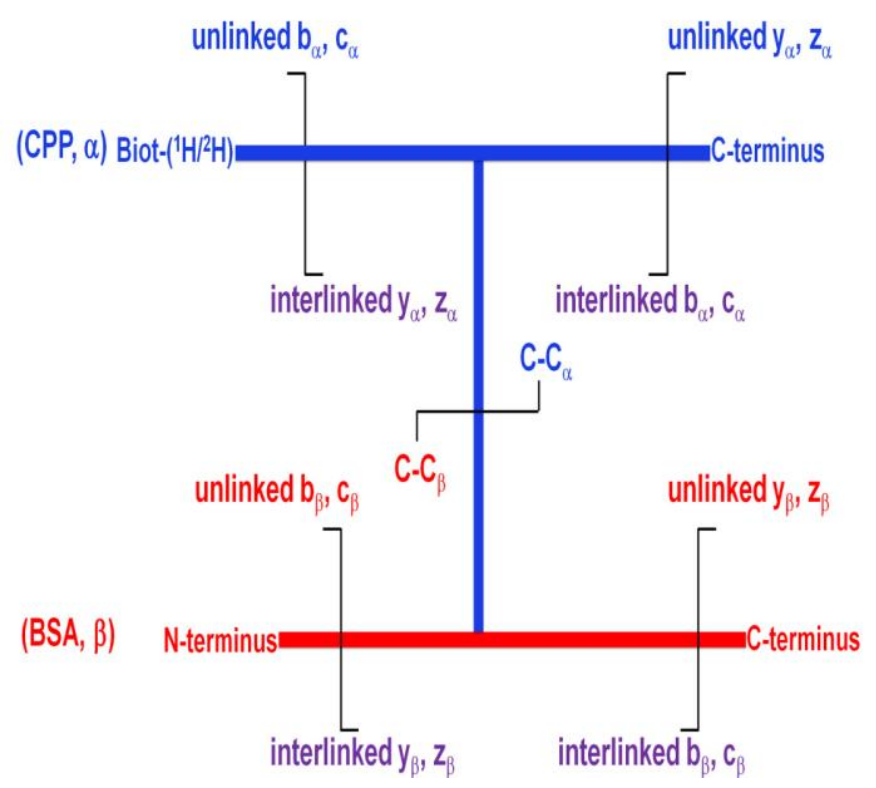

High-energy CID using a MALDI-TOF/TOF instrument: Keeping in mind that the upper limit for CID at high energy is approximately $\mathrm{m} / \mathrm{z} 3000$ [9], fragmentation of a precursor ion at $\mathrm{m} / \mathrm{z} 2803-2813$ $\left([\mathrm{M}+\mathrm{H}]^{+}\right)$requires manual optimization as well as relatively high amount of material allowing averaging of a high number of spectra (typically more than 30,000 laser shots). In addition, the selection window in the MALDI-TOF/TOF is relatively broad and does not allow selecting only one ion of the doublet without an important loss of precursor ions (already enriched by streptavidin affinity purification and therefore present in limiting amount). Therefore, we manually centered the selection window on the $\mathrm{m} / \mathrm{z}$ ratio 2809 with a low resolution $\mathrm{R}=30$, allowing the entire doublet to be selected and fragmented, minimizing the loss of material and combining heavy and light ions structural information in the same spectrum presented in Figure $\mathbf{4 a}$.

Fig. 4 


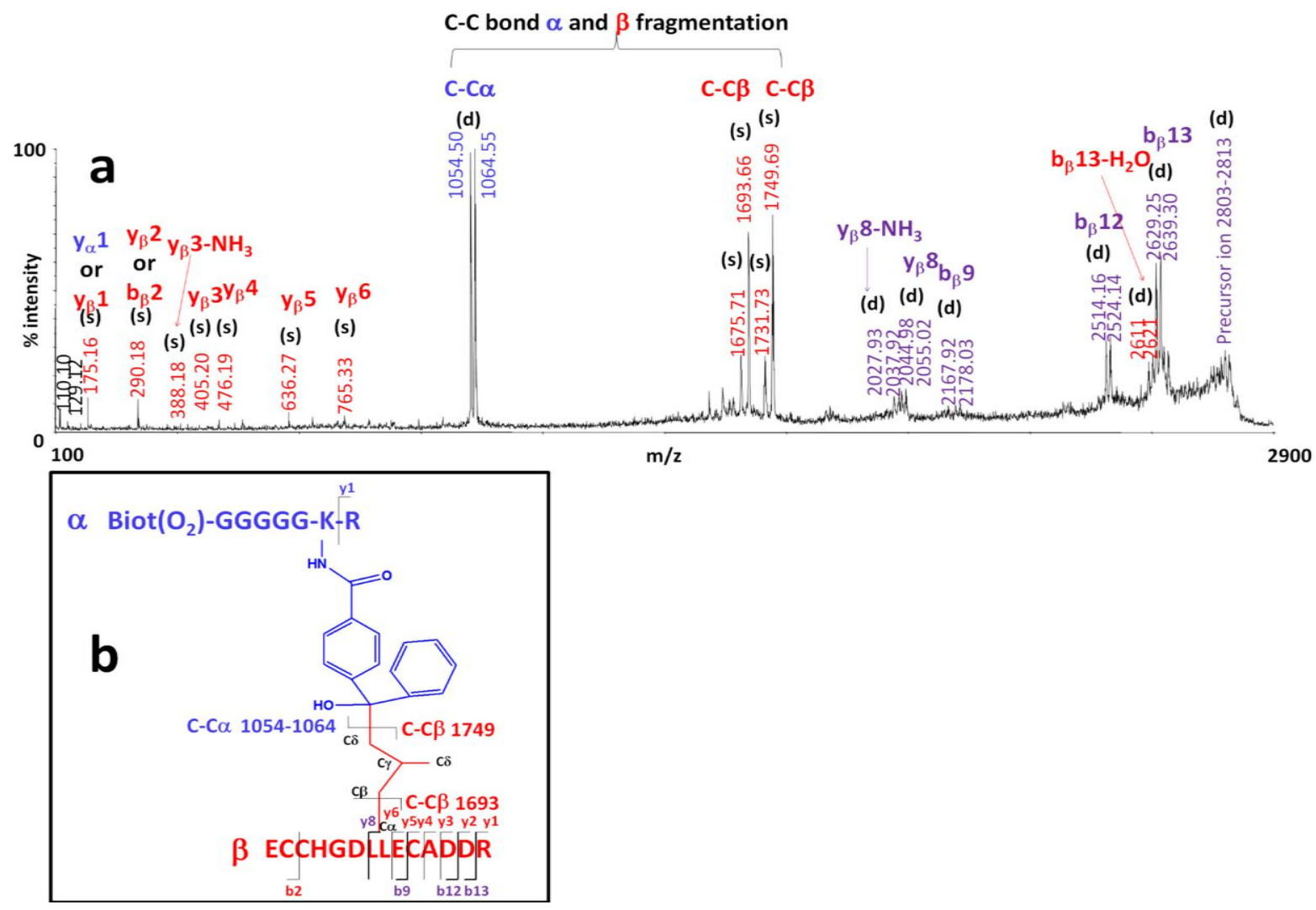

Both unlinked and interlinked y- and b- fragment ions (Figure $\mathbf{3}$ ) were identified (Table A1, electronic Supplemental Material), with possible neutral losses such as ammonia and/or water. They are localized with vertical bars in the photocross-linked peptide $2803-2813$ presented in Figure $\mathbf{4 b}$. They appeared either as singlet (s) or doublet (d) ions helping the reading of the peptide sequence, since the doublet revealed the presence of at least the photo(R/W $)_{9}$ pept(1-8) in the fragment ion (presence of the isotopically labelled Gly). No fragmentation was observed along the sequence of the photo(R/W) ${ }_{9}$ pept(1-8). The ion at $\mathrm{m} / \mathrm{z} 175$, corresponding to the $\mathrm{y} 1$ ion $(\mathrm{Arg})$ could arise from both peptide sequences ( $\alpha$ or $\beta$ ). As expected for high-energy CID, immonium ions corresponding to $\operatorname{Arg}$ and $\mathrm{His}$ at $\mathrm{m} / \mathrm{z} 129$ and 110 respectively were also observed.

Combining the information given by the $y$ - and $b$ - unlinked and interlinked fragment ions, we concluded that the created covalent bond occurred between photo(R/W $)_{9}$ pept(1-8) and Leu273 or Leu274 residues of the BSA peptide ${ }^{267}$ ECCHGDLLECADDR $^{280}$ (in bold). 
However, in this MALDI-TOF/TOF spectrum, the most intense ions observed did not correspond to bor $\mathrm{y}$ - fragment ions but to the unexpected fragmentation of $\mathrm{C}-\mathrm{C}$ bonds which theoretically require high energy to be broken. For instance, the ion at $\mathrm{m} / \mathrm{z}$ 1054-1064 (photo(R/W) ${ }_{9} \operatorname{pept}(1-8)$ ) and its complementary ion at $\mathrm{m} / \mathrm{z} 1749.69$ (BSA peptide) correspond to the fragmentation of the created covalent bond between the carbon of the $\mathrm{Bp}$ and the carbon of the photocross-linked Leu residue ( $\mathrm{C}$ $C \alpha$ or $C-C \beta)$ (Figure $4 b)$. The steric hindrance due to the presence of the two aromatic rings of the benzophenone (tertiary alcohol function with bulky substituents) probably weaken the C-C bond. This $C-C \alpha$ fragmentation corresponding to the release of the intact photo(R/W $)_{9} \operatorname{pept}(1-8)(\mathrm{m} / \mathrm{z} 1054$ 1064) was reproducibly the predominant fragment observed in the MALDI-TOF/TOF spectra of every photocross-linked peptides fragmented in this study. In this MALDI-TOF/TOF experiment, another possible explanation could be the absorption of the Bp moiety at the wavelength of the MALDI UV laser $(\lambda=355 \mathrm{~nm})$. The resulting excitation of the Bp could contribute to a local increase of internal energy, leading to the fragmentation of the $\mathrm{C}-\mathrm{C}$ bond. Another $\mathrm{C}-\mathrm{C}$ bond was fragmented in this example (fragment $\mathrm{C}-\mathrm{C} \beta$ at $\mathrm{m} / \mathrm{z}$ 1693.65), corresponding to the fragmentation in the lateral chain of the cross-linked Leu residue, between the $C \alpha$ and the $C \beta$ (Figure $4 b$ ) was generated, likely for the same reasons. This indicates that the site of photocross-linking is either on the $C \beta, \gamma$ or $\delta$ of the Leu side chain but not on the $C \alpha$. Both ions at $\mathrm{m} / \mathrm{z} 1749.69$ and 1693.65 also appeared with their neutral losses (water and/or water and ammonia).

The MALDI-TOF/TOF spectrum of the $\mathrm{m} / \mathrm{z} 2803-2813$ ions was therefore very informative and led to the identification of the covalent bond on the $\mathrm{C} \beta, \gamma$ or $\delta$ of the lateral chain of Leu273 or 274 of the BSA sequence ${ }^{267}$ ECCHGDLLECADDR $^{280}$ (in bold). With another photocross-linked peptide, observed at $\mathrm{m} / \mathrm{z} 2453-2463$ in Figure 2 and corresponding to the BSA peptide ${ }^{569}$ TVMENFVAFVDK $^{580}$ photocrosslinked to the photo(R/W) $)_{9} \operatorname{pept}(1-8)$, we determined precisely that the covalent bond occurred on the $\mathrm{C} \gamma$ of the Met571 (Figure A1, electronic Supplemental Material) thanks to the $\mathrm{C}-\mathrm{C}$ fragments information. The fragment at $\mathrm{m} / \mathrm{z} 1115-1125$ was attributed to the $\mathrm{C}-\mathrm{C} \alpha$ fragmentation between the 
photocross-linked carbon of the $\mathrm{Bp}$ and the $\mathrm{C} \gamma$ of the lateral chain of the Met571. However, the ability to get information on the carbon involved in the photocross-linking reaction cannot be generalized to every photocross-linked peptides manually inspected in this study as fragmentation in the lateral chain of the cross-linked residue is not always observed. Another point that is worth mentioning here is that Met was not always identified as the covalently linked residue in this interacting system showing that Bp reactivity is not always biased towards Met residues [21].

Low-energy CID and ETD using a nanoLC-ESI-LTQ/Orbitrap XL instrument: Low energy CID- and ETDbased fragmentation spectra were acquired using a nanoLC ESI-LTQ Orbitrap XL system. CID and ETD fragmentation were systematically alternated on the same precursor ions (multiprotonated ions produced by the ESI ion source) in an automatic data-dependent manner. Fragments were analyzed using the LTQ in both modes of fragmentation. To optimize fragmentation time and allow fragmenting only informative ions, the Masstag option of the Xcalibur software was used to select only doublets with the same intensity and a defined $\mathrm{m} / \mathrm{z}(10.06 / \mathrm{z})$ difference. We also chose to fragment successively both peaks of the doublets, corresponding to the light and heavy forms of the photocross-linked peptides. It is worth noting here that the Masstag option is based on mass difference $(10.06 / \mathrm{z})$ and on the relative abundance $(\%)$ of doublet intensity that should be between 70 and $100 \%$ to take into account experimental error in 1:1 mixture of both the light and the heavy forms of the peptides as well as difference of retention times due to deuteration.

ETD fragmentation: The ETD spectrum of the quadruply charged precursor ion $[\mathrm{M}+4 \mathrm{H}]^{4+}$ at $\mathrm{m} / \mathrm{z}$ 701.51-704.03 corresponding to our previous example $\left([\mathrm{M}+\mathrm{H}]^{+}\right.$ion at $\left.\mathrm{m} / \mathrm{z} 2803.07-2813.13\right)$ is shown in Figure 5. 
Fig. 5

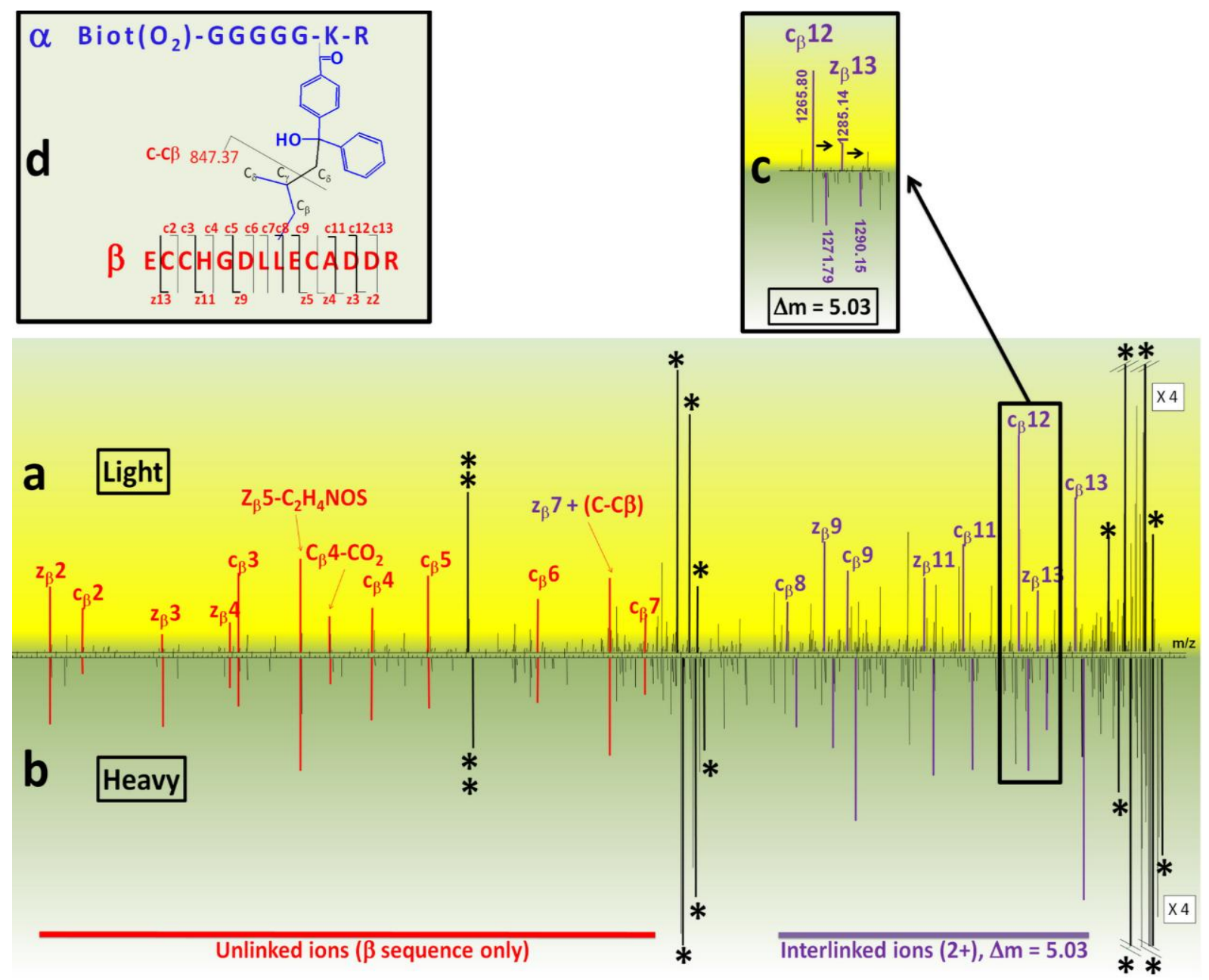

As usually observed with ETD, general efficiency of fragmentation is low since the most abundant ions are the precursor ion **, the charge-reduced precursor * (see Table A2, electronic Supplemental Material), irrespective of the use of supplemental activation (SA = $20 \%$ ) [14]. In addition, peaks corresponding to entire or partial side chain losses issued from charge-reduced precursor ions or $\mathrm{z}^{+\bullet}$ fragment ions were observed as summarized in Table A2, electronic Supplemental Material. For example, a loss of $\mathrm{C}_{2} \mathrm{H}_{4} \mathrm{NOS}^{\bullet}$ (90 mass units) from $\mathrm{z}^{+\bullet}$ or $\mathrm{z}^{2+\bullet}$ fragment ions containing a carbamidomethylated Cys in the $\mathrm{N}$-terminal region of the fragment was observed as described by Sun R-X. et al. [22]. The same loss of $\mathrm{C}_{2} \mathrm{H}_{4} \mathrm{NOS}^{\bullet}$ (90 mass units) was observed from the chargereduced ions whereas the loss of $\mathrm{C}_{4} \mathrm{H}_{8}$ (56 mass units) from a Leu residue side-chain was only 
observed from the charge-reduced $2+$ and $3+$ precursor ions. Possible mechanisms leading to these neutral losses are proposed in Scheme I.

Scheme I

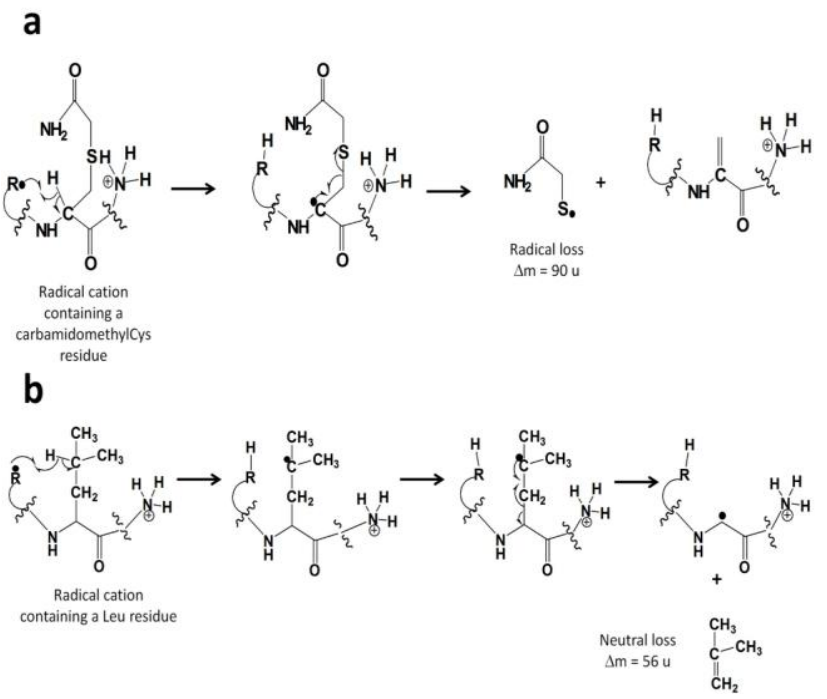

Besides these intense ions, an almost complete $c$ and $z^{\bullet}$ ions series, corresponding to unlinked and interlinked fragments were observed. Unlinked ions only appeared as monoprotonated c- or zfragment ions whereas interlinked ions appeared as doubly charged c- or z-ions. No higher charge states were observed, as expected from the ETD mechanism where one charge is lost due to electron-transfer to the 4+ peptide ion, leaving three charges which are distributed on the resulting fragments. As expected, the interlinked fragments which usually have the higher $\mathrm{m} / \mathrm{z}$ ratio, have the higher charge state. This was observed with other photocross-linked peptides examples such as in the ETD spectrum of the 4+ precursor ion corresponding to the covalent bond between the photo(R/W $)_{9}$ pept(1-8) and Ser89 of the BSA sequence ${ }^{89}$ SLHTLFGDELCK $^{100}$ (in bold), doublet observed at $\mathrm{m} / \mathrm{z}$ 2473.13-2483.17 $\left([\mathrm{M}+\mathrm{H}]^{+}\right)$in Figure 2. In this example, the c- interlinked fragment ions appear as $2+$ and/or $1+$ ions whereas the unlinked $z$ - fragment ions were always observed as $1+$ ions (Fig. A2, electronic Supplemental Material). 
Besides the conventional c- and z- fragment ions observed with the chosen example from Figure 5, and as already mentioned with high-energy (keV) CID, a fragment which could correspond to the fragmentation of a C-C $\beta$ bond, was observed in the ETD spectrum from both the light and heavy forms at $\mathrm{m} / \mathrm{z}$ 847.37. Based on the $\mathrm{m} / \mathrm{z}$ ratio, this fragment could be the result of the loss of the photo(R/W) pept(1-8) moiety (as a radical cation) from the $\mathrm{z}_{\beta} 7^{2+\bullet}$ due to the fragmentation between the $C_{\gamma}$ and the $C_{\delta}$ of the Leu274 side chain as represented in Figure $5 \mathrm{~d}$.

Crossing information given by these different fragments allowed confident assignment of the site of photocross-linking on Leu274 of the BSA peptide ${ }^{267}$ ECCHGDLLECADDR $^{280}$ (in bold). The presence of interlinked fragments ions was observed for every ETD spectra manually checked in this study and in most examples the series of c- and/or z- ions were almost complete. However, the possible C-C bond fragmentation was only seen in the ETD spectrum of the chosen example shown in Figure 5.

Low-energy CID: From the same LC-MS/MS run we obtained an independent CID dataset (Figure A3, electronic Supplemental Material). In the case of the chosen example (peptide $[\mathrm{M}+\mathrm{H}]^{+}$at $\mathrm{m} / \mathrm{z} 2803-$ 2813), it is important to note that CID-based fragmentation of the $3+$ and $2+$ precursor ions was not efficient enough and that only the MS2 spectrum of the 4+ precursor ion (Figure A3, Table A3, electronic Supplemental Material) revealed informative (higher internal energy due to a higher Coulomb repulsion). However, the signal-to-noise ratio of the CID spectra for both heavy and light versions of the photocross-linked peptide appeared much lower compared to ETD, and the number and intensity of unassigned species ("noise peaks", i.e. ions which are not part of the main b/y fragment ion series) was much higher.

Whatever the sequence of the photocross-linked peptide, low-energy CID spectra mostly presented singly charged unlinked fragment ions (only one example was found containing a doubly charged interlinked y ion, see Figure A4, electronic Supplemental Material). In similar experimental conditions, we could observe multiprotonated ions either charge-reduced ions or fragment ions in ETD. Therefore, the absence of multi charged fragment ions was quite unexpected for 
multiprotonated precursor ions, such as a $4+$ ion. This could be the result of further consecutive fragmentation of the higher charge state fragment ions.

An extensive fragmentation of the biotin $(\mathrm{O})_{2}-\mathrm{G}_{5}\left({ }^{1} \mathrm{H} /{ }^{2} \mathrm{H}\right)-\mathrm{K}(\mathrm{Bp})-\mathrm{R}$ tag ( $\alpha$ sequence) led to $\mathrm{b}$ - diagnostic ions series at m/z 259.08 (Biot), 316.10 (Biot-G), 373.12 (Biot-GG), 430.14 (Biot-GGG), 487.16 (BiotGGGG) and 544.18 (Biot-GGGGG) (values are given here for the light version) which are the signature of the presence of the photo(R/W $)_{9}$ pept(1-8) in the sequence of the precursor ion. Generally no $y$ ions were observed in the $\alpha$ sequence for the $\mathrm{m} / \mathrm{z}$ range (200-1500) of the MS2 spectra. In the case of the chosen example (peptide $[\mathrm{M}+\mathrm{H}]^{+}$at $\mathrm{m} / \mathrm{z} 2803-2813$ ), some of the expected $\mathrm{y}$ - and $\mathrm{b}$ - unlinked fragment ions of the $\beta$ sequence were present. No interlinked ions were observed in the low-energy CID MS2 spectrum. These ions should however exist as multiprotonated ions and were possibly further fragmented leading to low $\mathrm{m} / \mathrm{z}$ fragments which could not be easily attributed in the MS2 spectrum and contributed to the noise observed in the spectrum. Crossing information given by the unlinked $y$ - and $b$ - fragment ions was not sufficient to precisely determine the photocross-linked residue. However, we could restrict the interaction zone to the residues L273 or L274 from the $\beta$ sequence. In all other manually inspected MS/MS spectra mostly unlinked fragments were observed and most of the time these unlinked fragments were not sufficient to unambiguously determine the cross-linking position (additional examples are shown in Figures $A 2 a$ and $A 4 a$, electronic Supplemental Material).

Compared to low-energy CID, ETD fragmentation led to the production of numerous and relatively abundant interlinked ions which constitute the unambiguous signature of the existence of a covalent bond between the two (photocross-linked) peptides. The presence of these interlinked ions in ETD spectra was reproducible whatever the sequence of the photocross-linked peptide species and revealed particularly useful to narrow down the number of residues possibly involved in the crosslinking reaction (Figures $A 2, A 3, A 4$, electronic Supplemental Material). The signal-to-noise ratio of the ETD spectra appeared much improved compared to CID and the number and intensity of unassigned species was much lower. Taken together, these features of ETD may contribute to an 
increase in confidence of assignment of fragment ions. Based on our results obtained with different photocross-linked peptide sequences, we can conclude that ETD is more suitable for the identification and characterization of covalently linked peptides. However, when fragmentation is not complete, both CID and ETD fragmentation can be complementary in obtaining information about the characterization of the interaction zones. It is worth noting here that even if HCD could not lead to informative spectra for most of the enriched photocross-linked peptides, HCD MS2 spectra of the quadruply charged ion at $\mathrm{m} / \mathrm{z} 701.5-704.5\left([\mathrm{M}+\mathrm{H}]^{+}\right.$at $\mathrm{m} / \mathrm{z} 2803-2813$ in Figure 2$)$ allowed the characterization of this photocross-linked peptide and the localization of the covalent bond on Leu274 of the BSA sequence ${ }^{267}$ ECCHGDLLECADDR $^{280}$ (in bold) (Table A4, electronic Supplemental Material), only based on the information given by the $1+$ unlinked $b$ - and $y$ - fragment ions since no interlinked ions were present in the spectrum.

Finally, low-energy CID did not allow fragmentation of the C-C bond of the cross-linker in our study. This fragmentation was always easily observed using keV collision in MALDI-TOF/TOF and can be observed in some ETD spectra (only one example in this study, corresponding to a consecutive fragmentation). Therefore, even if MALDI-TOF/TOF cannot be easily automated in an on-line workflow (nanoLC coupling and automatic acquisition) and thus would not be suitable for high throughput proteomic/interactomic analysis, it can provide occasional and very valuable information in the case of a cross-linking-based structural studies. However, low-energy CID fragmentation of the C-C bond has been recently reported in a similar study concerning the interaction between the photoreactive peptide M13 and its partner protein CaM using the para-benzoyl phenylalanine as the photoprobe [23]. In this case the fragmentation of the newly formed C-C bond is believed to be specific of cross-linked products with $\mathrm{N}$-terminal and oxidized methionines and results from consecutive fragmentation.

\section{Conclusions}


In this study, we optimized a very efficient affinity purification step that can be realized with photocross-linking reaction mixtures obtained in vitro or in cellulo. Moreover, we show that the number of MS2 data acquired can be considerably restricted using a targeted approach involving isotopic labeling coupled to the Masstag option of Xcalibur which allows fragmentation of only relevant isotopically labelled ions. These two strategies, both aiming at a targeting of the generated data, can reveal extremely useful in the case of complex photocross-linking mixtures involving unknown partners. Actually this approach aiming at the identification of in vitro or in cellulo interaction partners of a molecule/peptide of interest can be applied to numerous others peptides providing that the biotin and the photoprobe are not dissociated during the enzymatic digestion. The photoactivable peptide under study must thus be carefully designed avoiding for example the presence of lysine or arginine residue between the biotin and the photoprobe in the case of a tryptic digestion. In addition, it will be necessary to ensure that these biotin and photoprobe are not modifying the peptide original biological properties. In order to limit the effect of these features on the peptide activity we suggest to position the biotin and the photoactivable probe either $\mathrm{N}$-term or C-term of the peptide of interest not to affect the core structure of the latter.

Besides these considerations, it is important to note that, even if not trivial, manual identification and characterization of the photocross-linked species was feasible in the present study since we worked in vitro, with a simple context of two known partner sequences, one of them being a short biotinylated and isotopically labelled photoreactive peptide. This manual interpretation of the MS2 spectra revealed the high potential of ETD for the identification and characterization of photocrosslinked peptides due to the production of interlinked ions that are usually not observed in CID spectra. However, in the case of a low yield of ETD or CID fragmentation, we showed that combining information given by both fragmentation techniques helped for the identification of the cross-linked residues. Consequently, we describe a general procedure to facilitate the identification of interacting partners using photocross-linking that can be extended to more complex in vitro or in cellulo interacting systems. The whole strategy is summarized in Figure 6. 
Fig. 6

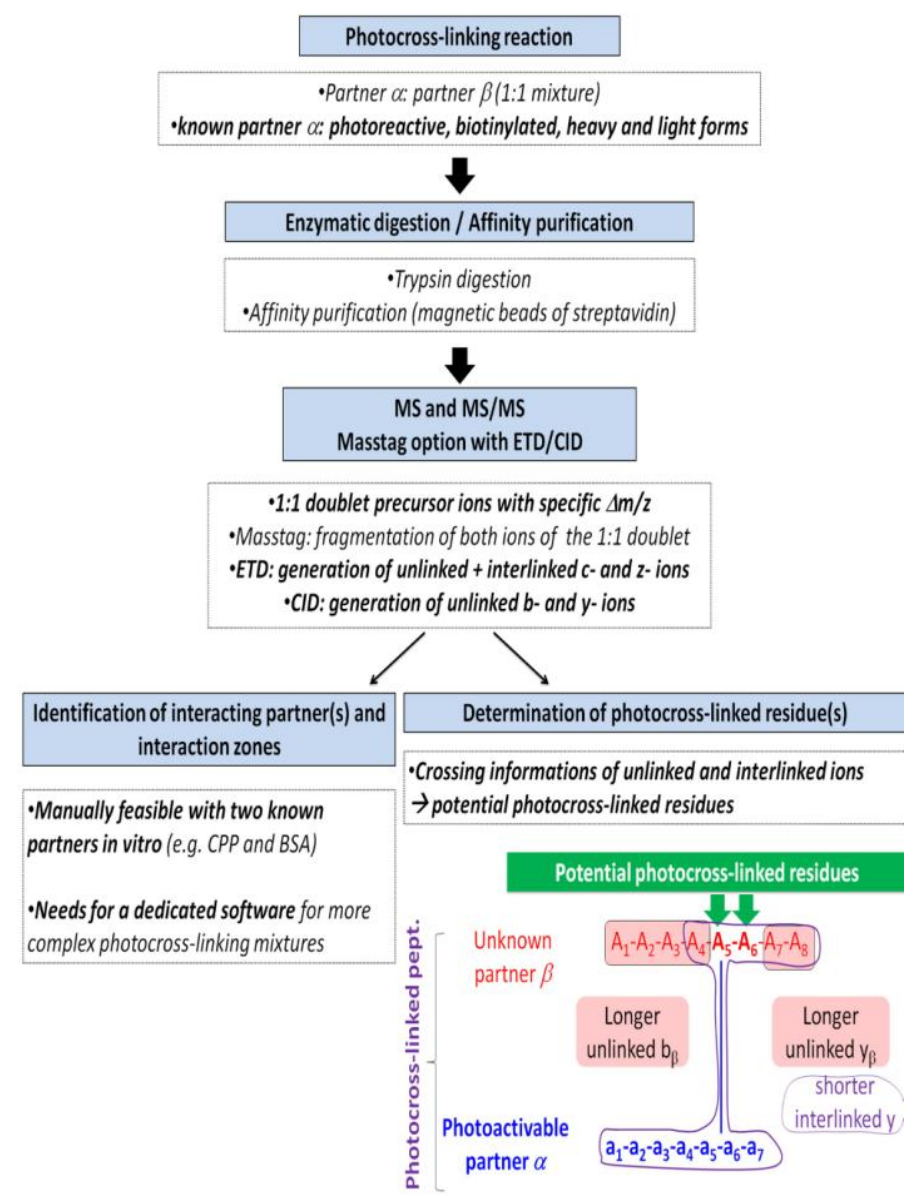

To conclude, automation of the data treatment is absolutely required to extend this strategy to unknown interacting partners. Most of the widely applied searching programs, such as Mascot are not developed and thus are not suitable, for analyzing fragmentation spectra originating from photocross-linked peptides even when, as in our case, at least one of the peptide partners is known and can thus be defined as a peptide modification (an example is shown in Figure A5, electronic Supplemental Material) where the photo(R/W $)_{9}$ pept(1-8) was defined as a modification occurring on selective residues for the Mascot search. We consider that StavroX, an open source software developed by M. Gotze et al. [6] is very promising for the search of photocross-linking products. It actually allowed us to confirm most of the manually identified photocross-linked peptides. We performed the search with CID data only, ETD data only or with both CID and ETD data. Searching CID and ETD data at the same time led to significant improvements of the cross-link candidates score. 
However we noticed that the localization of residue involved in the cross-linking reaction was difficult solely based on the cross-link candidate score. Indeed scores are usually proportional to the number of identified fragments for a peptide. However some fragments such as short interlinked fragments may be more important than others to precisely determine a cross-linking position. Consequently combining CID and ETD data in a specific search algorithm using information given by the shorter interlinked and the longer unlinked ions observed in the MS2 spectra (as proposed in summarized strategy from Fig. 6) should allow to really reduce the number of possible cross-linked residues and thus to gain in structural resolution. A recent study from Liu, F. et al. [24] describes EThcD fragmentation for other type of covalently bond peptides: disulfide bridged peptides. In this study, ETD preferentially leads to the cleavage of the S-S bonds, generating two disulfide cleaved peptides and the subsequent $\mathrm{HCD}$ fragmentation primarily targets unreacted and charge reduced precursor ions, inducing peptide fragmentation. Therefore, according to the results obtained in our study, this type of analysis could be the next step for the efficient identification/characterization of enriched photocross-linked peptides with ETD generating interlinked c- and z- fragment ions and HCD targeting the unreacted species to produce unlinked $b$ - and $y$ ions.

\section{Acknowledgments}

We acknowledge Dr. L. Matheron for proof reading and scientific discussions. 
References

1. Singh, P.,Panchaud, A.,Goodlett, D. R.: Chemical cross-linking and mass spectrometry as a low-resolution protein structure determination technique. Anal Chem 82 (7), 2636-2642(2010).

2. Vasilescu, J.,Guo, X., Kast, J.: Identification of protein-protein interactions using in vivo crosslinking and mass spectrometry. Proteomics 4 (12), 3845-3854(2004).

3. Davis, L.,Chin, J. W.: Designer proteins: applications of genetic code expansion in cell biology. Nat Rev Mol Cell Biol 13 (3), 168-182(2012).

4. Suchanek, M.,Radzikowska, A.,Thiele, C.: Photo-leucine and photo-methionine allow identification of protein-protein interactions in living cells. Nat Methods 2 (4), 261-267(2005).

5. Tanaka, Y.,Bond, M. R.,Kohler, J. J.: Photocrosslinkers illuminate interactions in living cells. Mol Biosyst 4 (6), 473-480(2008).

6. Gotze, M.,Pettelkau, J.,Schaks, S.,Bosse, K.,Ihling, C. H.,Krauth, F.,Fritzsche, R.,Kuhn, U.,Sinz, A.: StavroX--a software for analyzing crosslinked products in protein interaction studies. J Am Soc Mass Spectrom 23 (1), 76-87(2012).

7. Biemann, K.: Contributions of mass spectrometry to peptide and protein structure. Biomed Environ Mass Spectrom 16 (1-12), 99-111(1988).

8. Roepstorff, P.,Fohlman, J.: Proposal for a common nomenclature for sequence ions in mass spectra of peptides. Biomed Mass Spectrom 11 (11), 601(1984).

9. Wells, J. M.,McLuckey, S. A.: Collision-induced dissociation (CID) of peptides and proteins. Methods Enzymol 402, 148-185(2005).

10. Syka, J. E.,Coon, J. J.,Schroeder, M. J.,Shabanowitz, J.,Hunt, D. F.: Peptide and protein sequence analysis by electron transfer dissociation mass spectrometry. Proc Natl Acad Sci U S A 101 (26), 9528-9533(2004).

11. Good, D. M.,Wirtala, M.,McAlister, G. C.,Coon, J. J.: Performance characteristics of electron transfer dissociation mass spectrometry. Mol Cell Proteomics 6 (11), 1942-1951(2007).

12. Mikesh, L. M.,Ueberheide, B.,Chi, A.,Coon, J. J.,Syka, J. E.,Shabanowitz, J.,Hunt, D. F.: The utility of ETD mass spectrometry in proteomic analysis. Biochim Biophys Acta 1764 (12), 18111822(2006).

13. Molina, H.,Matthiesen, R.,Kandasamy, K.,Pandey, A.: Comprehensive comparison of collision induced dissociation and electron transfer dissociation. Anal Chem 80 (13), 4825-4835(2008).

14. Swaney, D. L.,McAlister, G. C.,Wirtala, M.,Schwartz, J. C.,Syka, J. E.,Coon, J. J.: Supplemental activation method for high-efficiency electron-transfer dissociation of doubly protonated peptide precursors. Anal Chem 79 (2), 477-485(2007).

15. Li, X.,Cournoyer, J. J.,Lin, C.,O'Connor, P. B.: The effect of fixed charge modifications on electron capture dissociation. J Am Soc Mass Spectrom 19 (10), 1514-1526(2008).

16. Clavier, S.,Du, X.,Sagan, S.,Bolbach, G.,Sachon, E.: An integrated cross-linking-MS approach to investigate cell penetrating peptides interacting partners. EuPA Open Proteomics 3 (52), 229238(2014).

17. Delaroche, D.,Cantrelle, F. X.,Subra, F.,Van Heijenoort, C.,Guittet, E.,Jiao, C. Y.,Blanchoin, L.,Chassaing, G.,Lavielle, S.,Auclair, C.,Sagan, S.: Cell-penetrating peptides with intracellular actinremodeling activity in malignant fibroblasts. J Biol Chem 285 (10), 7712-7721(2010).

18. Sachon, E.,Girault-Lagrange, S.,Chassaing, G.,Lavielle, S.,Sagan, S.: Analogs of Substance P modified at the C-terminus which are both agonist and antagonist of the NK-1 receptor depending on the second messenger pathway. J. Peptide Res. 59, 232-240(2002).

19. Sachon, E.,Bolbach, G.,Chassaing, G.,Lavielle, S.,Sagan, S.: Cgamma H2 of Met174 side chain is the site of covalent attachment of a substance $P$ analog photoactivable in position 5. J Biol Chem 277 (52), 50409-50414(2002).

20. Mourey, R. J.,Estevez, V. A.,Marecek, J. F.,Barrow, R. K.,Prestwich, G. D.,Snyder, S. H.: Inositol 1,4,5-trisphosphate receptors: labeling the inositol 1,4,5-trisphosphate binding site with photoaffinity ligands. Biochemistry 32 (7), 1719-1726(1993). 
21. Rihakova, L.,Deraet, M.,Auger-Messier, M.,Perodin, J.,Boucard, A. A.,Guillemette, G.,Leduc, R.,Lavigne, P.,Escher, E.: Methionine proximity assay, a novel method for exploring peptide ligandreceptor interaction. J Recept Signal Transduct Res 22 (1-4), 297-313(2002).

22. Sun, R. X.,Dong, M. Q.,Song, C. Q.,Chi, H.,Yang, B.,Xiu, L. Y.,Tao, L.,Jing, Z. Y.,Liu, C.,Wang, L. H.,Fu, Y.,He, S. M.: Improved peptide identification for proteomic analysis based on comprehensive characterization of electron transfer dissociation spectra. J Proteome Res 9 (12), 6354-6367(2010).

23. Pettelkau, J.,Ihling, C. H.,Frohberg, P.,van Werven, L.,Jahn, O.,Sinz, A.: Reliable identification of cross-linked products in protein interaction studies by $13 \mathrm{C}$-labeled p-benzoylphenylalanine. J Am Soc Mass Spectrom 25 (9), 1628-1641

24. Liu, F.,van Breukelen, B.,Heck, A. J.: Facilitating Protein Disulfide Mapping by a Combination of Pepsin Digestion, Electron Transfer Higher Energy Dissociation (EThCD), and a Dedicated Search Algorithm SlinkS. Mol Cell Proteomics 13 (10), 2776-2786(2014). 
Tables

\begin{tabular}{|c|c|c|c|c|}
\hline Exp. $m / z$ & Theo. $\mathrm{m} / \mathrm{z}$ & $\begin{array}{l}\Delta \text { mass } \\
\text { (ppm) }\end{array}$ & $\begin{array}{l}\text { photo }(\mathrm{R} / \mathrm{W})_{9} \\
\text { tryptic pept. } \\
\alpha \text { sequence }\end{array}$ & $\begin{array}{c}\text { BSA tryptic pept. } \\
\beta \text { sequence }\end{array}$ \\
\hline $1054.44-1064.49$ & $1054.45-1064.52$ & 19 & pep $1-8$ & - \\
\hline $1402.54-1407.57(2+)$ & $1402.05-1407.09(2+)$ & 14 & pep 1-8 & ${ }^{267}$ECCCHGDLLECADDR $^{280}$ \\
\hline $1641.78-1651.84$ & 1641.81-1651.87 & 18 & pep $1-9$ & ${ }^{456} \mathrm{VGTR}^{459}$ \\
\hline $1702.74-1712.81$ & $1702.77-1712.84$ & 17 & pep $1-8$ & 205|ETMR 209 \\
\hline $1871.88-1881.94$ & $1871.87-1881.93$ & 5 & pep $1-8$ & 562ATEEQLK568 \\
\hline $2040.95-2051.01$ & $2040.98-2051.05$ & 20 & pep 1-8 & ${ }^{29}$ SEIAHRFK $^{36}$ \\
\hline 2303.03-2313.09 & $2313.06-2313.13$ & 17 & pep 1-8 & ${ }^{35}$ FKDLGEEHFK $^{44}$ \\
\hline $2453.11-2463.17$ & $2453.13-2463.20$ & 12 & pep 1-8 & ${ }^{569}$ TVMENFVAFVDK $^{580}$ \\
\hline $2473.10-2483.17$ & $2473.13-2483.20$ & 12 & pep $1-8$ & ${ }^{89}$ SLHTLFGDELCK ${ }^{100}$ \\
\hline 2531.93-2541.99 & $2531.96-2542.03$ & 16 & pep 1-8 & ${ }^{106}$ ETYGDMADCCEK $^{117}$ \\
\hline 2803.08-2813.14 & 2803.10-2813.17 & 10 & pep 1-8 & ${ }^{267} E^{2 C C H G D L L E C A D D R}{ }^{280}$ \\
\hline
\end{tabular}

Table 1: Attribution of the doublet ions observed in the MALDI-TOF spectrum from Figure 1. Observed and theoretical $\mathrm{m} / \mathrm{z}$ are presented in the two first columns with the $\Delta$ mass in $\mathrm{ppm}$ in the third column. Tryptic peptides corresponding to the sequence of the photo(R/W) $($ in blue) and BSA (in red) that fit for the observed mass of the photocross-linked species are given in the last two columns. The photocross-linked peptide at $\mathrm{m} / \mathrm{z} 2803-2813$ is in bold since it was chosen as an example for this study. 


\section{Appendices}

Fig. A1 High-energy CID (MALDI-TOF/TOF) spectrum of the singly charged parent ion at $\mathrm{m} / \mathrm{z} 2453$ 2463. The observed $y$ - and $b$ - fragment ions are labelled and summarized in the tables for both peptides sequences, the CPP (blue) and the BSA (red) trypsic peptide. C-C bond fragments are observed

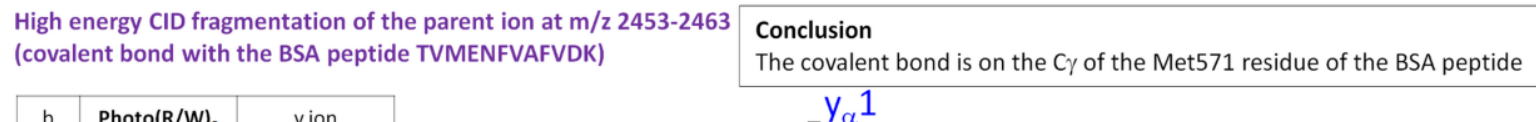

\begin{tabular}{|c|c|c|}
\hline $\begin{array}{c}\text { b } \\
\text { ion }\end{array}$ & $\begin{array}{c}\text { Photo(R/W) } \\
\text { pept(1-8) }\end{array}$ & y ion \\
\hline & biot & \\
\hline & G & \\
\hline & G & \\
\hline & G & \\
\hline & G & \\
\hline & G & \\
\hline & (Bp) K & \\
\hline & R & 175.16 \\
\hline
\end{tabular}

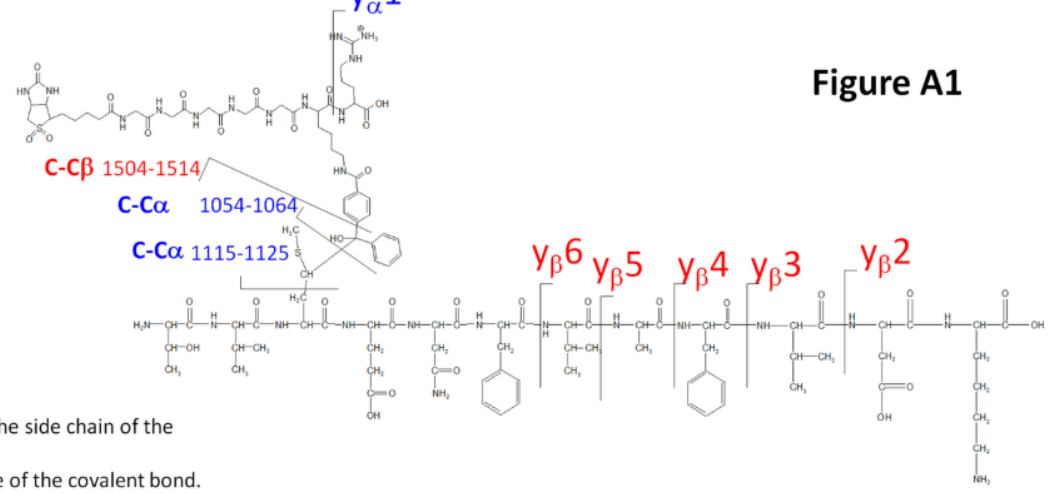

Met571 residue of the BSA peptide.

$\mathrm{m} / \mathrm{z}$ 1054-1054 : C-C bond fragmentation at the site of the covalent bond.

\begin{tabular}{|l|l|l|}
\hline $\begin{array}{c}\text { b } \\
\text { ion }\end{array}$ & $\begin{array}{c}\text { BSA } \\
\text { seq }\end{array}$ & y ion \\
\hline & T & \\
\hline & V & \\
\hline & M & \\
\hline & E & \\
\hline N & \\
\hline & F & \\
\hline & V & 678.36 \\
\hline & A & 579.28 \\
\hline & F & 508.28 \\
\hline & V & 361.24 \\
\hline D & 262.14 \\
\hline K & \\
\hline & & \\
\hline
\end{tabular}

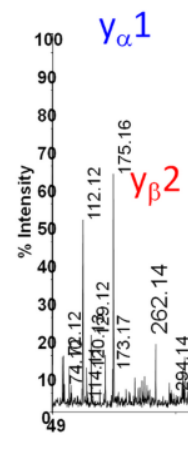

C-C fragmentations

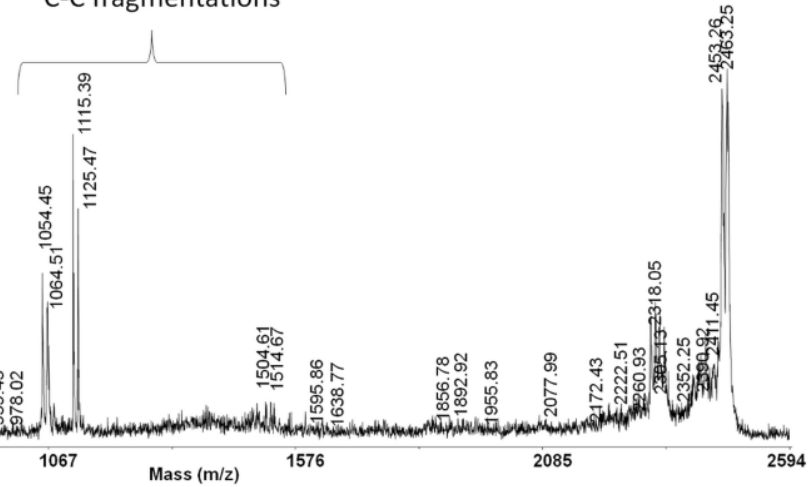


Fig. A2 a) Low-energy CID fragmentation spectrum, b) ETD fragmentation spectrum of the quadruply charged precursor ion at $\mathrm{m} / \mathrm{z}$ 619.54-622.06 $([\mathrm{M}+\mathrm{H}]+$ at $\mathrm{m} / \mathrm{z} 2473-2483)$. Fragment ions issued from the CPP are labelled in blue whereas the ones issued from the BSA peptide are labelled in red

CID fragmentation of the ion at $\mathrm{m} / \mathrm{z} 2473-2483$.
Automatic selection of the precursor ion: $4+$ at $m / 3$

Automatic selection of the precursor ion: 4+ at m/z 619.54-622.06 Figure A2

\begin{tabular}{|c|c|c|}
\hline bion & BSA seq & Y ion \\
\hline & S & \\
\hline & L & \\
\hline & H & \\
\hline & T & 1082.52 \\
\hline & L & 981.47 \\
\hline & F & 868.39 \\
\hline & G & \\
\hline & D & \\
\hline & E & \\
\hline & L & 420.23 \\
\hline & C & 307.14 (low intensity) \\
\hline & K & \\
\hline
\end{tabular}

Conclusion:

CID fragmentation led to the characterization of the Ser, Leu or His

residue (in brackets) as the photocross-linked residue.

We chose to represent the photocross-linked peptide with the covalent

bond on the $C \beta$ of the Ser.

\begin{tabular}{|c|c|c|c|}
\hline a ion & b ion & $\begin{array}{c}\text { Photo(R/W) } \\
(\mathbf{1 - 8})\end{array}$ & y ion \\
\hline & 259.08 & biot & \\
\hline $288.10-290.11$ & $316.10-318.10$ & G & \\
\hline $345.12-349.10$ & $373.12-377.12$ & G & \\
\hline & $430.14-436.14$ & G & \\
\hline & $487.16-495.16$ & G & \\
\hline & & G & \\
\hline & & (Bp) K & \\
\hline & & R & 175.12 \\
\hline
\end{tabular}

b1 b2 b3 b4

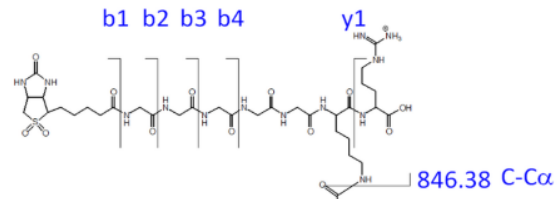

No interlinked ions are observed 


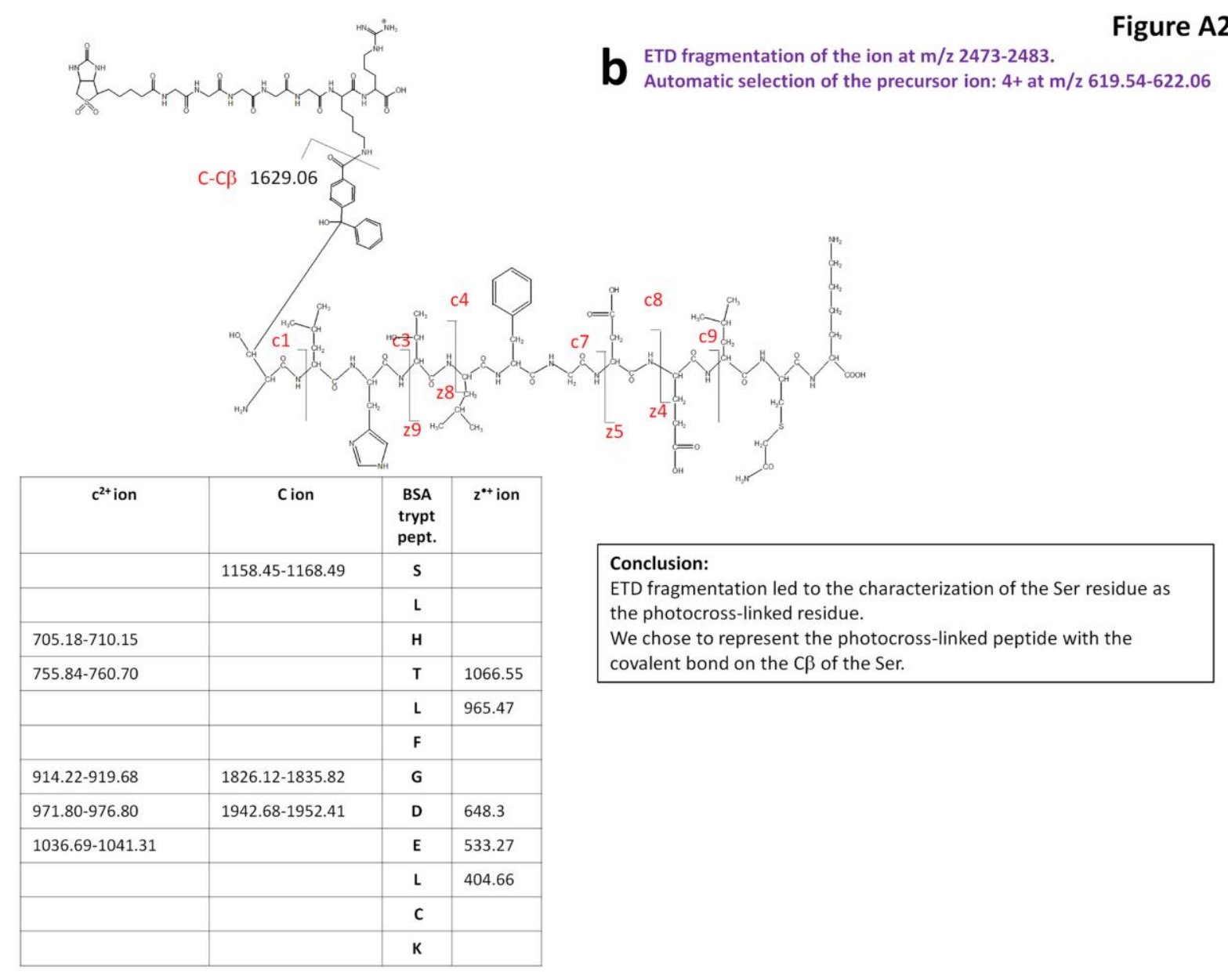


Fig. A3 Low-energy CID fragmentation of the $4+$ ion at $\mathrm{m} / \mathrm{z} 701.5-704.5$ corresponding to the chosen example ion at $\mathrm{m} / \mathrm{z} 2803-2813$ for the $(\mathrm{M}+\mathrm{H})^{+}$ion. a) CID spectrum of the light form at $\mathrm{m} / \mathrm{z} 701.5 ; b$ ) CID spectrum of the heavy form at $\mathrm{m} / \mathrm{z} 704.5 ; \mathrm{c}$ ) structure of the photocross-linked peptide with $\alpha$ being the structure of the CPP (in blue) and $\beta$ the structure of the BSA peptide (in red). $b$ - and $y$ fragment ions are labelled in the spectra and marked on the scheme c). lons in blue are from the $\alpha$ sequence, in red from the $\beta$ sequence

Figure A3

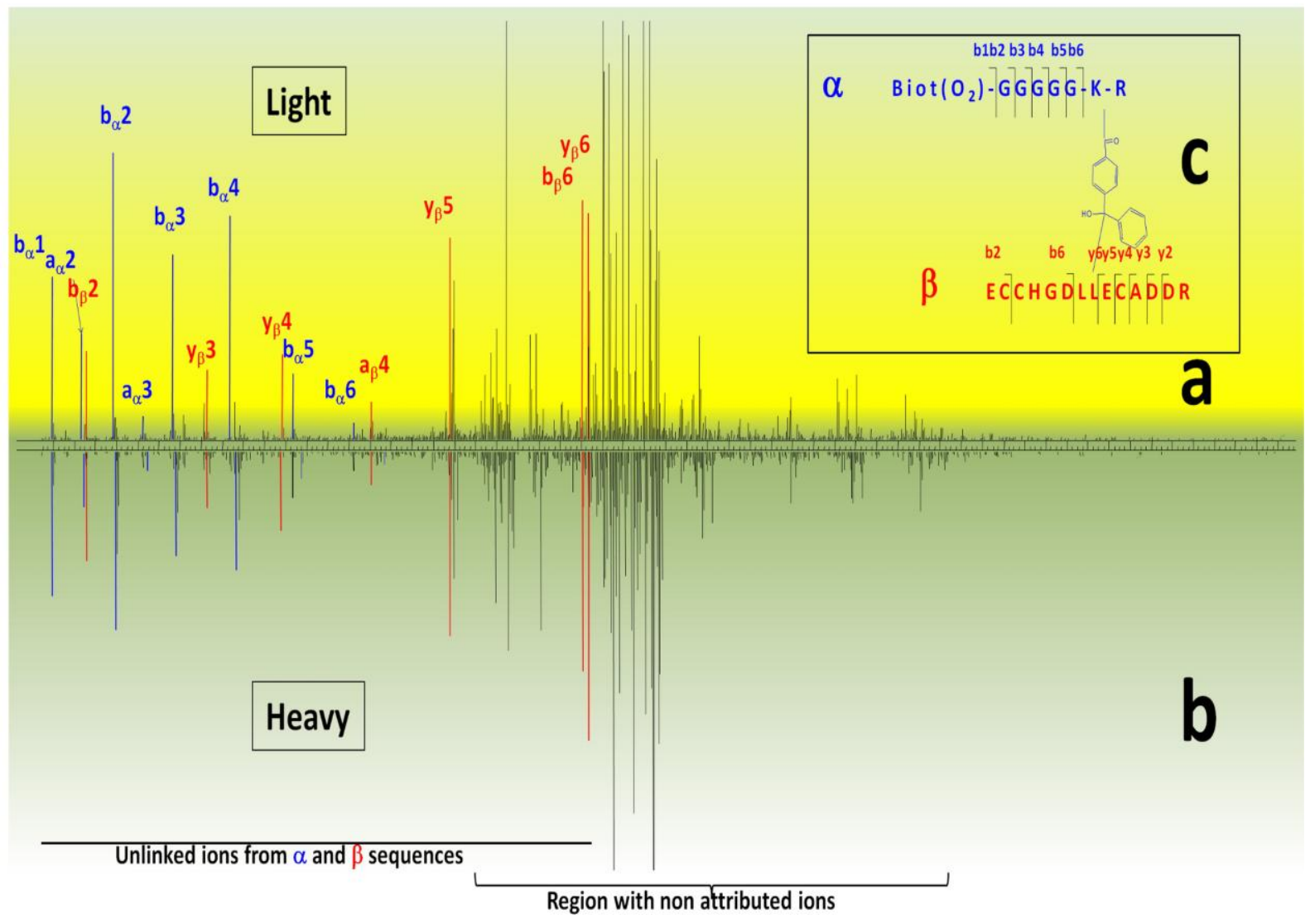


Fig. A4 a) Low-energy CID fragmentation spectrum, b) ETD fragmentation spectrum of the triply charged precursor ion at $\mathrm{m} / \mathrm{z} 615-618([\mathrm{M}+\mathrm{H}]+$ at $\mathrm{m} / \mathrm{z} 1843-1853)$. Fragment ions issued from the CPP are labelled in blue whereas the ones issued from the BSA peptide are labelled in red

Low-energy CID fragmentation of the ion at $\mathrm{m} / \mathrm{z}$ 1843-1853

The automatically selected precursor ion is $3+$ at $\mathrm{m} / \mathrm{z} 615-618$

\begin{tabular}{|c|c|c|}
\hline bions & $\begin{array}{c}\text { BSA } \\
\text { sequence }\end{array}$ & y ions \\
\hline & L & \\
\hline 213 & V & \\
\hline & T & $816-821(2+)+$ - - loss of $\mathrm{H}_{2} \mathrm{O}$ \\
\hline 429 & D & \\
\hline & L & \\
\hline & T & \\
\hline & K & \\
\hline
\end{tabular}

\begin{tabular}{|c|c|c|}
\hline$b$ ions & $\begin{array}{l}\text { Photo(R/W) })_{9} \text { pept(1- } \\
\text { 8) }\end{array}$ & $y$ ions \\
\hline 259 & Biot & \\
\hline 316 & G & \\
\hline 373 & G & \\
\hline 430 & G & \\
\hline \multirow[t]{4}{*}{487} & G & \\
\hline & G & \\
\hline & $\mathrm{K}(\mathrm{Bp})$ & \\
\hline & $R$ & \\
\hline
\end{tabular}

charge reduced species are observed:

$2+$ at $\mathrm{m} / 2$ 922-927 +/- loss of $\mathrm{H}_{2} \mathrm{O}$ and $-28(\mathrm{CO})$
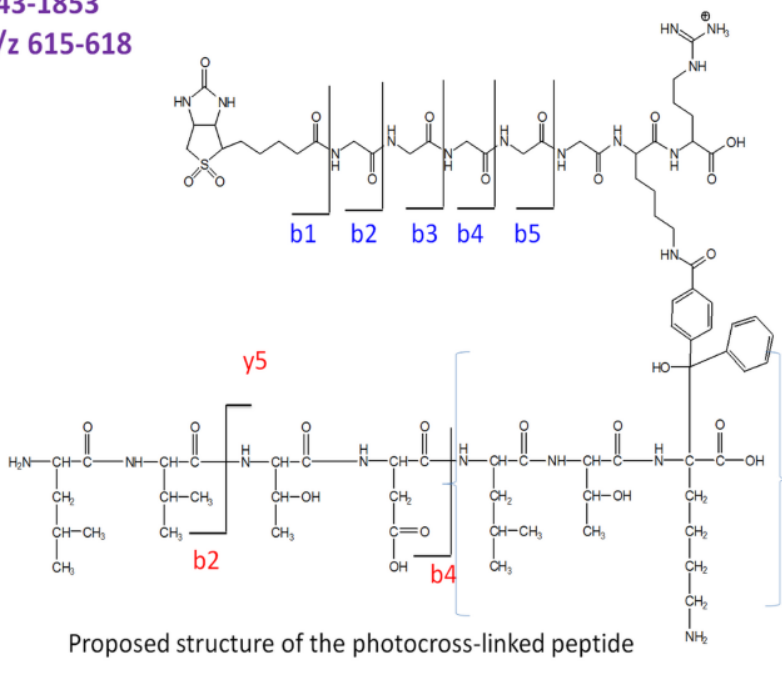

Conclusion:

Characterization of the photocross-linking site on the

residues $\mathrm{LT}$ or $\mathrm{K}$ (in brackets) of the BSA sequence.

The covalent link is arbitrary represented on the $\mathrm{K}$ residue. 


\begin{tabular}{|c|c|c|}
\hline$C^{+}$ & BSA Seq & $Z^{+}$ \\
\hline & L & \\
\hline & $\mathrm{V}$ & \\
\hline & $\mathrm{T}$ & \\
\hline & $\mathrm{D}$ & \\
\hline $1714-1724$ & $\mathrm{~L}$ & $1399-1409$ \\
\hline $1686-1696(-\mathrm{CO})$ & & \\
\hline & $\mathrm{K}$ & \\
\hline
\end{tabular}

charge reduced species are observed:

$2+$ ion at $\mathrm{m} / 2$ 922-927 $+/-\mathrm{H}_{2} \mathrm{O}$ and -28 (CO)

\begin{tabular}{|c|c|c|}
\hline $\mathrm{C}^{+}$ & $\begin{array}{r}\text { Photo(R/W) } \\
\text { 8) }\end{array}$ & $\mathrm{Z}^{+}$ \\
\hline & Biot & \\
\hline & G $1-$ & \\
\hline & G & \\
\hline & G & \\
\hline & G & \\
\hline & G & \\
\hline & K(Bp) & \\
\hline & R & 1285 \\
\hline
\end{tabular}

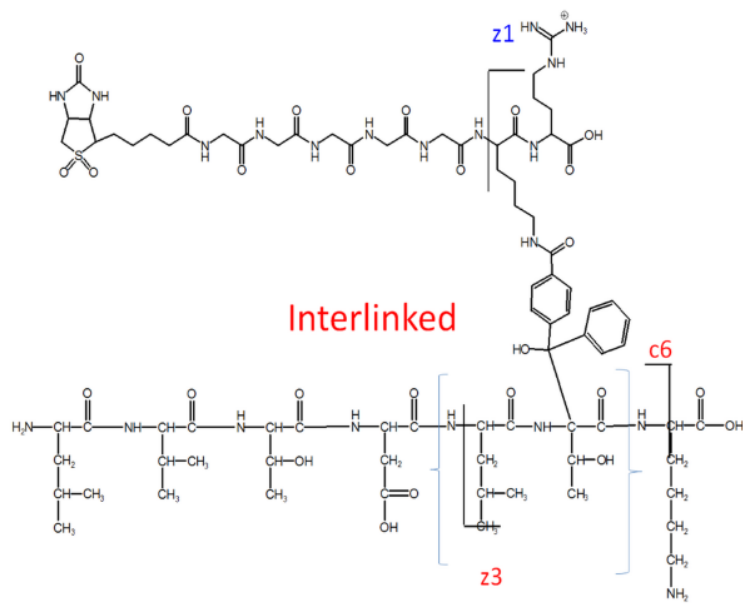

Conclusion:

With ETD we characterized the $L$ or $T$ residues

(in brackets) as the photocross-linked residue.

We represented arbitrary the covalent link on

$\mathrm{T}$. 
Fig. A5 Examples of results obtained using Protein Discoverer 1.3 to search photocross-linking data obtained using the interacting system photo $(\mathrm{R} / \mathrm{W})_{9}$ : BSA. The photo $(\mathrm{R} / \mathrm{W})_{9} \mathrm{CPP}$ has been defined as a modification that can possibly occur on the 20 different residues. The search with the modification on a Tyr a) and on a Leu b) are presented. The characterized peptides bearing this modification appear as non significant hits (red dots, FDR $>5 \%$ )

a search with the $(\mathrm{R} / \mathrm{W})_{9}$ modification defined as a modification of a Tyr residue

\begin{tabular}{|c|c|c|c|c|c|c|c|c|c|c|c|c|c|c|c|}
\hline Proteins & Peeptoes & Search hout & Resulfiliters & is Peppoid & de Confidence & Search Summary & & & & & & & & & \\
\hline 因 & A2 & Sequer & & ; PSM/S & \& Proteins & i Proten Groups & Proten Group Accessions 5 & Modficaboons & $\Delta C n$ & lonscore & Exp Value & Chrgrge & $\mathrm{MH}+[\mathrm{Dz}]$ & $\Delta M[p p m]$ & $R T[$ min] \\
\hline$\mp 1$ & $\Gamma 0$ & HPEAVSVLLR & & 1 & 2 & & 1. P02769 & & 0.0000 & 20 & L.4E:001 & 2 & 128337.7306 & 1.85 & 33.34 \\
\hline$\pm \overline{2}$ & $\Gamma 0$ & EEATEECCAK & & 1 & 1 & & 1. P02769 & Cg(Carbamidomethy)); C10(Carbamidomethy) & 0.0000 & 57 & 8.0E:006 & 2 & 1502661528 & 0.97 & 29.20 \\
\hline$\mp 3$ & $\Gamma 0$ & DDPHACSTVFO & & 1 & 1 & & 1902769 & CG(Carbamidomethy) & 0.0000 & 30 & $5.5 E-003$ & 2 & 155465471 & 1.11 & 31.20 \\
\hline$\pm \overline{4}$ & $\Gamma 0$ & ECCHGDULECAOD & & 4 & 10 & & 1. P02769 & 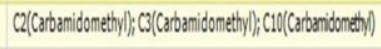 & 0.0000 & 29 & 166.003 & 3 & 1749666446 & 1.06 & 28.94 \\
\hline+5 & $\Gamma 0$ & HPYFAPEELIWA & & 3 & 2 & & 1. P02769 & & 0.0000 & 44 & 1.75 .003 & 3 & 1888.92624 & .0 .33 & 37,72 \\
\hline$\pm \overline{6}$ & $\Gamma 0$ & EYGDMADCCEK & & 1 & 2 & & 1. P02769 & 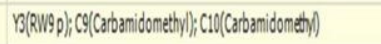 & 0.0000 & 15 & $2.95 \cdot 002$ & 3 & 2531.96262 & 2.17 & 31.37 \\
\hline
\end{tabular}

\section{b Search with the $(R / W)_{9}$ modification defined as a modification of a Leu residue}

\begin{tabular}{|c|c|c|c|c|c|c|c|c|c|c|c|c|c|c|}
\hline Proteins & Pepopdes & 5 Sesch hoput Resultiliter: & 5 Pepdide & Carfibence & Search Summan & & & & & & & & & \\
\hline 专 & A2 & Sequence & ;PSM/s & : Protens & aproten Groups & Proten Group Accessions : & Modfictoors & $\Delta C$ & lonscore & Exp Value & Charge & $\mathrm{NHH}+[\mathrm{DB}]$ & $\Delta M[p p m]$ & $\operatorname{RT}[$ [nin] $]$ \\
\hline \pm 1 & $\lceil 0$ & HPEYAVSNLR & 1 & 2 & & 1. 902769 & & 0.0000 & 20 & 1.4501: & 2 & 1283.71306 & 1.85 & 33.34 \\
\hline \pm 2 & $\ulcorner 0$ & BeaneEccak & 1 & 1 & & 1. 02269 & 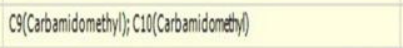 & 0.0000 & 57 & 8.0E:006 & 2 & 1502615158 & 0.97 & 29.20 \\
\hline \pm 3 & $\Gamma 0$ & DDPAACSTVFOK & 1 & 1 & & 1. 902769 & Cof(cribaridomethy) & 0,0000 & 30 & 5.56003 & 2 & 1554655471 & 1.11 & 31.20 \\
\hline 74 & $\Gamma 0$ & ECCHGDLLECADOR & 4 & 10 & & 1. 90269 & 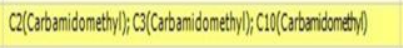 & 0.0000 & 29 & 1.650 .03 & 3 & 1749,66446 & 1.06 & 28.94 \\
\hline \pm 5 & $\Gamma 0$ & HPPFAPELLWAKK & 3 & 2 & & 1. 90269 & & 0.0000 & 4 & 2250.03 & 3 & 18889.9624 & .0 .33 & $37,2.2$ \\
\hline F 6 & $\Gamma 0$ & AKAWSIAR & 2 & 2 & & 1. 90269 & LL(RMgp) & 0.0000 & 18 & $1,75+100$ & 3 & 20550.2304 & 0.05 & 30.53 \\
\hline \pm 7 & $\ulcorner 0$ & Ecch Gol Eatod & 4 & 10 & & 1. 90269 & 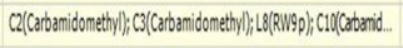 & 0.0000 & 16 & 6.0.0.02 & 3 & 28030.09899 & 1.23 & 31.60 \\
\hline 78 & $\ulcorner 0$ & EECCGOLLECAOOR & 4 & 10 & & 1. 90269 & 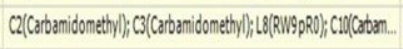 & 0.0000 & 20 & 7850102 & 3 & 2813:15897 & 0.08 & 31.29 \\
\hline
\end{tabular}


Table A1 Attribution of the $b$ - and $y$ - fragment ions of the doublet parent ion at $\mathrm{m} / \mathrm{z} 2803-2813$

(MALDI-TOF/TOF). First column corresponds to the observed $\mathrm{m} / \mathrm{z}$, second column to the $b$ - or $y$ - type of ion and the two last columns correspond to the tryptic peptide sequences of the photocross-linked ion. Unlinked ions are either in red (originating from $\beta$ sequence) or in blue (originating from $\alpha$ sequence). Interlinked ions are in purple (since they contain both $\alpha$ and $\beta$ sequences parts). Cystein residues are carbamidomethylcysteine, (s) for singlet and (d) doublet. The cells filled in grey correspond to $\mathrm{C}-\mathrm{C}$ bond fragmentations

\begin{tabular}{|c|c|c|c|}
\hline observed $\mathrm{m} / \mathrm{z}$ & $\begin{array}{l}\text { Fragment ion type } \\
\text { CID (high energy) }\end{array}$ & $\begin{array}{c}\alpha \text { seq. } \\
\text { Photo(R/W) }{ }_{9} \text { pept. (1-8) }\end{array}$ & $\begin{array}{c}\beta \text { seq. } \\
\text { BSA peptide ECCHGDLLECADDR }\end{array}$ \\
\hline (s) 110.10 & immonium & - & $\mathrm{I}(\mathrm{H})$ \\
\hline (s) 129 & immonium & - & $\mathrm{I}(\mathrm{R})$ \\
\hline (s) 175.16 & unlinked $y_{\beta}$ & $\mathrm{y}_{\alpha} 1 \rightarrow \mathrm{R}$ & or $y_{\beta} 1 \rightarrow R$ \\
\hline (s) 290.18 & unlinked $b_{\beta}$ or unlinked $y_{\beta}$ & - & $\mathrm{b}_{\beta} 2 \rightarrow \mathrm{EC}$ or $\mathrm{y}_{\beta} 2 \rightarrow \mathrm{DR}$ \\
\hline (s) 388.17 & unlinked $\mathrm{y}_{\beta}-\mathrm{NH}_{3}$ & - & $y_{\beta} 3 \rightarrow D D R$ \\
\hline (s) 405.20 & unlinked $y_{\beta}$ & - & $y_{\beta} 3 \rightarrow D D R$ \\
\hline (s) 476.19 & unlinked $\mathrm{y}_{\beta}$ & - & $Y_{\beta} 4 \rightarrow A D D R$ \\
\hline (s) 636.26 & unlinked $\mathrm{y}_{\beta}$ & - & $y_{\beta} 5 \rightarrow C A D D R$ \\
\hline (s) 765.33 & unlinked $\mathrm{y}_{\beta}$ & - & $y_{\beta} 6 \rightarrow$ ECADDR \\
\hline (d) $1054.50-1064.55$ & $\begin{array}{c}\text { C-C bond fragment }{ }_{\alpha} \\
\text { (complementary ion of 1749.69) }\end{array}$ & $\operatorname{Biot}\left(\mathrm{O}_{2}\right)-\mathrm{G}_{5}\left({ }^{1} \mathrm{H} /{ }^{2} \mathrm{H}\right)-\mathrm{K}(\mathrm{Bp})-\mathrm{R}$ & - \\
\hline (s) 1693.66 & $\mathrm{C}-\mathrm{C}$ bond fragment ${ }_{\beta}$ & - & $\begin{array}{l}\text { ECCHGDLLECADDR fragmentation } \\
\text { in the side chain of the photocross- } \\
\text { linked } L(C \alpha \text { and } C \beta) \text {. }\end{array}$ \\
\hline (s) 1749.69 & $\begin{array}{c}\mathrm{C}-\mathrm{C} \text { bond fragment } \\
\text { (complementary ion of } 1054.50 \text { - } \\
10645.55 \text { ) }\end{array}$ & - & $\begin{array}{l}\text { ECCHGDLLECADDR fragmentation } \\
\text { at the photocross-linking site. }\end{array}$ \\
\hline (d) 2027.93-2037.2 & interlinked $\mathrm{y}_{\beta}-\mathrm{NH}_{3}$ & $\operatorname{Biot}\left(\mathrm{O}_{2}\right)-\mathrm{G}_{5}\left({ }^{1} \mathrm{H} /{ }^{2} \mathrm{H}\right)-\mathrm{K}(\mathrm{Bp})-\mathrm{R}$ & $\mathrm{y}_{\beta} 8 \rightarrow$ LLECADDR \\
\hline (d) 2044.98-2055.02 & interlinked $\mathrm{y}_{\beta}$ & $\operatorname{Biot}\left(\mathrm{O}_{2}\right)-\mathrm{G}_{5}\left({ }^{1} \mathrm{H} /{ }^{2} \mathrm{H}\right)-\mathrm{K}(\mathrm{Bp})-\mathrm{R}$ & $\mathrm{y}_{\beta} 8 \rightarrow$ LLECADDR \\
\hline (d) $2140.90-2150.97$ & interlinked $a_{\beta}$ & $\operatorname{Biot}\left(\mathrm{O}_{2}\right)-\mathrm{G}_{5}\left({ }^{1} \mathrm{H} /{ }^{2} \mathrm{H}\right)-\mathrm{K}(\mathrm{Bp})-\mathrm{R}$ & $a_{\beta} 9 \rightarrow$ ECCHGDLLE \\
\hline (d) 2167.92-2178.03 & interlinked $b_{\beta}$ & $\operatorname{Biot}\left(\mathrm{O}_{2}\right)-\mathrm{G}_{5}\left({ }^{1} \mathrm{H} /{ }^{2} \mathrm{H}\right)-\mathrm{K}(\mathrm{Bp})-\mathrm{R}$ & $b_{\beta} 9 \rightarrow$ ECCHGDLLE \\
\hline (d) $2514.16-2524.14$ & interlinked $b_{\beta}$ & $\operatorname{Biot}\left(\mathrm{O}_{2}\right)-\mathrm{G}_{5}\left({ }^{1} \mathrm{H} /{ }^{2} \mathrm{H}\right)-\mathrm{K}(\mathrm{Bp})-\mathrm{R}$ & $\mathrm{b}_{\beta} 12 \rightarrow$ ECCHGDLLECAD \\
\hline (d) $2611-2621$ & interlinked $\mathrm{b}_{\beta}-\mathrm{H}_{2} \mathrm{O}$ & $\operatorname{Biot}\left(\mathrm{O}_{2}\right)-\mathrm{G}_{5}\left({ }^{1} \mathrm{H} /{ }^{2} \mathrm{H}\right)-\mathrm{K}(\mathrm{Bp})-\mathrm{R}$ & $\mathrm{b}_{\beta} 13 \rightarrow$ ECCHGDLLECADD \\
\hline (d) $2629.25-2639.30$ & interlinked $b_{\beta}$ & $\operatorname{Biot}\left(\mathrm{O}_{2}\right)-\mathrm{G}_{5}\left({ }^{1} \mathrm{H} /{ }^{2} \mathrm{H}\right)-\mathrm{K}(\mathrm{Bp})-\mathrm{R}$ & $\mathrm{b}_{\beta} 13 \rightarrow$ ECCHGDLLECADD \\
\hline
\end{tabular}


Table A2 Attribution of the c- and z-fragment ions observed in the ETD spectrum (ESI-LTQ/Orbitrap $\mathrm{XL}$ ) of the 4+ parent ion corresponding to the $[\mathrm{M}+\mathrm{H}]^{+}$at 2803.07-2813.13. First column corresponds to the observed $\mathrm{m} / \mathrm{z}$, second column to the c- or z- type of ion and the two last columns correspond to the tryptic peptide sequences of the photocross-linked ion. Unlinked ions are either in red (when originating from the $\beta$ sequence) or in blue (when originating from the $\alpha$ sequence). Interlinked ions are in purple (since they contain both $\alpha$ and $\beta$ sequences parts). Grey lines correspond to C-C bond fragmentations. Cysteine residues are carbamidomethylcysteine, (s) for singlet and (d) for doublet. The cells filled in grey correspond to $\mathrm{C}-\mathrm{C}$ bond fragmentations. Cystein residues are all carbamidomethylated. The precursor ion as well as the charge-reduced species and their neutral losses are in black

\begin{tabular}{|c|c|c|c|}
\hline Observed $\mathrm{m} / \mathrm{z}$ & Fragment ion type ETD & $\alpha$ seq.: Photo(R/W $)_{9}$ pept. (1-8) & $\beta$ seq.: ECCHGDLLECADDR \\
\hline (s) 274.10 & unlinked $z_{\beta}{ }^{+}$ & - & $\mathrm{z} 2 \rightarrow \mathrm{DR}$ \\
\hline (s) 306.11 & unlinked $c_{\beta}$ & - & $\mathrm{c} 2 \rightarrow \mathrm{EC}$ \\
\hline (s) 389.13 & unlinked $z_{\beta}{ }^{+}$ & - & $\mathrm{z} 3 \rightarrow \mathrm{DDR}$ \\
\hline (s) 460.15 & unlinked $z_{\beta}{ }^{+}$ & - & $\mathrm{Z} 4 \rightarrow \mathrm{ADDR}$ \\
\hline (s) 466.16 & unlinked $c_{\beta}$ & - & $\mathrm{C} 3 \rightarrow \mathrm{ECC}$ \\
\hline (s) 529.18 & unlinked $\mathrm{z}_{\beta}{ }^{+}-\mathrm{C}_{2} \mathrm{H}_{4}$ NOS. & - & $z 5 \rightarrow C A D D R$ \\
\hline (s) 560.17 & unlinked $\mathrm{c}_{\beta}-\mathrm{CO}_{2}$ & & $\mathrm{C} 4 \rightarrow \mathrm{ECCH}$ \\
\hline (s) 603.25 & unlinked $c_{\beta}$ & - & $\mathrm{c} 4 \rightarrow \mathrm{ECCH}$ \\
\hline (s) 660.29 & unlinked $c_{\beta}$ & - & $\mathrm{c} 5 \rightarrow \mathrm{ECCHG}$ \\
\hline (s) 775.27 & unlinked $c_{\beta}$ & - & $\mathrm{C} 6 \rightarrow \mathrm{ECCHGD}$ \\
\hline (s) 847.37 & $\begin{array}{l}z_{\beta} 7 \text { with the loss of the CPP moiety } \\
\text { (C-C bond fragmentation } \beta \text { ) }\end{array}$ & - & $z 7 \rightarrow$ LECADDR \\
\hline (s) 888.37 & unlinked $c_{\beta}$ & - & $\mathrm{c} 7 \rightarrow \mathrm{ECCHGDL}$ \\
\hline (d) 1028.12-1033.15 & interlinked $\mathrm{c}_{\beta}^{2+}$ & $\operatorname{Biot}\left(\mathrm{O}_{2}\right)-\mathrm{G}_{5}\left({ }^{1} \mathrm{H} /{ }^{2} \mathrm{H}\right)-\mathrm{K}(\mathrm{Bp})-\mathrm{R}$ & $\mathrm{C} 8 \rightarrow \mathrm{ECCHGDLL}$ \\
\hline (d) $1072.45-1077.47$ & interlinked $z_{\beta}^{2+-}$ & $\operatorname{Biot}\left(\mathrm{O}_{2}\right)-\mathrm{G}_{5}\left({ }^{1} \mathrm{H} /{ }^{2} \mathrm{H}\right)-\mathrm{K}(\mathrm{Bp})-\mathrm{R}$ & $z 9 \rightarrow$ DLLECADDR \\
\hline (d) 1092.47-1097.49 & interlinked $c_{\beta}{ }^{2+}$ & $\operatorname{Biot}\left(\mathrm{O}_{2}\right)-\mathrm{G}_{5}\left({ }^{1} \mathrm{H} /{ }^{2} \mathrm{H}\right)-\mathrm{K}(\mathrm{Bp})-\mathrm{R}$ & C9 $\rightarrow$ ECCHGDLLE \\
\hline (d) $1169.52-1174.60$ & interlinked $z_{\beta}{ }^{2++}$ & $\operatorname{Biot}\left(\mathrm{O}_{2}\right)-\mathrm{G}_{5}\left({ }^{1} \mathrm{H} /{ }^{2} \mathrm{H}\right)-\mathrm{K}(\mathrm{Bp})-\mathrm{R}$ & $z 11 \rightarrow$ HGDLLECADDR \\
\hline (d) $1207.78-1212.85$ & interlinked $\mathrm{c}_{\beta}{ }^{2+}$ & $\operatorname{Biot}\left(\mathrm{O}_{2}\right)-\mathrm{G}_{5}\left({ }^{1} \mathrm{H} /{ }^{2} \mathrm{H}\right)-\mathrm{K}(\mathrm{Bp})-\mathrm{R}$ & C11 $\rightarrow$ ECCHGDLLECA \\
\hline (d) $1265.80-1271.79$ & interlinked $\mathrm{c}_{\beta}{ }^{2+}$ & $\operatorname{Biot}\left(\mathrm{O}_{2}\right)-\mathrm{G}_{5}\left({ }^{1} \mathrm{H} /{ }^{2} \mathrm{H}\right)-\mathrm{K}(\mathrm{Bp})-\mathrm{R}$ & $\mathrm{C} 12 \rightarrow \mathrm{ECCHGDLLECAD}$ \\
\hline (d) 1285.14-129015 & Interlinked $\mathrm{z}_{\beta}^{2+-}-\mathrm{C}_{2} \mathrm{H}_{4} \mathrm{NOS}$ & $\operatorname{Biot}\left(\mathrm{O}_{2}\right)-\mathrm{G}_{5}\left({ }^{1} \mathrm{H} /{ }^{2} \mathrm{H}\right)-\mathrm{K}(\mathrm{Bp})-\mathrm{R}$ & $z 13 \rightarrow C C H G D L L E C A D D R$ \\
\hline (d) 1323.01-1328.11 & interlinked $\mathrm{c}_{\beta}^{2+}$ & $\operatorname{Biot}\left(\mathrm{O}_{2}\right)-\mathrm{G}_{5}\left({ }^{1} \mathrm{H} /{ }^{2} \mathrm{H}\right)-\mathrm{K}(\mathrm{Bp})-\mathrm{R}$ & $\mathrm{C} 13 \rightarrow \mathrm{ECCHGDLLECADD}$ \\
\hline (d) $701.51-704.03$ & {$[\mathrm{M}+4 \mathrm{H}]^{4+}$} & $\operatorname{Biot}\left(\mathrm{O}_{2}\right)-\mathrm{G}_{5}\left({ }^{1} \mathrm{H} /{ }^{2} \mathrm{H}\right)-\mathrm{K}(\mathrm{Bp})-\mathrm{R}$ & ECCHGDLLECADDR \\
\hline (d) $935.02-938.38$ & {$[\mathrm{M}+3 \mathrm{H}]^{3+\bullet}$ or $[\mathrm{M}+3 \mathrm{H}]^{3+}$} & $\operatorname{Biot}\left(\mathrm{O}_{2}\right)-\mathrm{G}_{5}\left({ }^{1} \mathrm{H} /{ }^{2} \mathrm{H}\right)-\mathrm{K}(\mathrm{Bp})-\mathrm{R}$ & ECCHGDLLECADDR \\
\hline (d) $1402.04-1407.07$ & {$[\mathrm{M}+2 \mathrm{H}]^{2+\bullet}$ or $[\mathrm{M}+2 \mathrm{H}]^{2+}$} & $\operatorname{Biot}\left(\mathrm{O}_{2}\right)-\mathrm{G}_{5}\left({ }^{1} \mathrm{H} /{ }^{2} \mathrm{H}\right)-\mathrm{K}(\mathrm{Bp})-\mathrm{R}$ & ECCHGDLLECADDR \\
\hline (d) $929.55-933.40$ & {$[\mathrm{M}+3 \mathrm{H}]^{3+\bullet}$ or $[\mathrm{M}+3 \mathrm{H}]^{3+}-\mathrm{H}_{2} \mathrm{O}$} & $\operatorname{Biot}\left(\mathrm{O}_{2}\right)-\mathrm{G}_{5}\left({ }^{1} \mathrm{H} /{ }^{2} \mathrm{H}\right)-\mathrm{K}(\mathrm{Bp})-\mathrm{R}$ & ECCHGDLLECADDR \\
\hline (d) $916.43-919.43$ & {$[\mathrm{M}+3 \mathrm{H}]^{3+\bullet}$ or $[\mathrm{M}+3 \mathrm{H}]^{3+}-\mathrm{C}_{4} \mathrm{H}_{8}$} & $\operatorname{Biot}\left(\mathrm{O}_{2}\right)-\mathrm{G}_{5}\left({ }^{1} \mathrm{H} /{ }^{2} \mathrm{H}\right)-\mathrm{K}(\mathrm{Bp})-\mathrm{R}$ & ECCHGDLLECADDR \\
\hline (d) $1393.85-1398.88$ & {$[\mathrm{M}+2 \mathrm{H}]^{2+\bullet}$ or $[\mathrm{M}+2 \mathrm{H}]^{2+}-\mathrm{H}_{2} \mathrm{O}$} & $\operatorname{Biot}\left(\mathrm{O}_{2}\right)-\mathrm{G}_{5}\left({ }^{1} \mathrm{H} /{ }^{2} \mathrm{H}\right)-\mathrm{K}(\mathrm{Bp})-\mathrm{R}$ & ECCHGDLLECADDR \\
\hline (d) $1374.07-1379.16$ & {$[\mathrm{M}+2 \mathrm{H}]^{2+\bullet}$ or $[\mathrm{M}+2 \mathrm{H}]^{2+}-\mathrm{C}_{4} \mathrm{H}_{8}$} & $\operatorname{Biot}\left(\mathrm{O}_{2}\right)-\mathrm{G}_{5}\left({ }^{1} \mathrm{H} /{ }^{2} \mathrm{H}\right)-\mathrm{K}(\mathrm{Bp})-\mathrm{R}$ & ECCHGDLLECADDR \\
\hline
\end{tabular}


Table A3 Low-energy CID fragmentation of the $4+$ ion at $\mathrm{m} / \mathrm{z} 701.5-704.5$ corresponding to the chosen example at $\mathrm{m} / \mathrm{z} 2803-2813$ for the $(\mathrm{M}+\mathrm{H})^{+}$ion. Attribution of the $b$ - and $y$ - fragment ions. Cysteine residues are carbamidomethylcysteine, (s) for singlet and (d) doublet. Unlinked ions are either in red (originating from $\beta$ sequence) or in blue (originating from $\alpha$ sequence)

\begin{tabular}{|c|c|c|c|}
\hline Observed $\mathrm{m} / \mathrm{z}$ & $\begin{array}{l}\text { Fragment ion type } \\
\text { low-energy CID }\end{array}$ & $\begin{array}{c}\alpha \text { sequence } \\
\text { Photo(R/W)gpept. (1-8) }\end{array}$ & $\begin{array}{c}\beta \text { sequence } \\
\text { BSA peptide ECCHGDLLECADDR }\end{array}$ \\
\hline (s) 259.10 & unlinked $b_{\alpha}$ & $" b_{\alpha} 1 " \rightarrow \operatorname{Biot}\left(O_{2}\right)$ & - \\
\hline (d) $288.1-290.1$ & unlinked $\mathrm{a}_{\alpha}$ & $a_{\alpha} 2 \rightarrow \operatorname{Biot}\left(O_{2}\right)-G$ & - \\
\hline (s) 290.14 & unlinked $\mathrm{y}_{\beta}$ & - & $y_{\beta} 2 \rightarrow D R$ \\
\hline (s) 291.09 & unlinked $b_{\beta}$ & - & $\mathrm{b}_{\beta} 2 \rightarrow \mathrm{EC}$ \\
\hline (d) $316.1-318.1$ & unlinked $b_{\alpha}$ & $\mathrm{b}_{\alpha} 2 \rightarrow \operatorname{Biot}\left(\mathrm{O}_{2}\right)-\mathrm{G}$ & - \\
\hline (d) $345.1-349.1$ & unlinked $\mathrm{a}_{\alpha}$ & $\mathrm{a}_{\alpha} 3 \rightarrow \operatorname{Biot}\left(\mathrm{O}_{2}\right)-\mathrm{GG}$ & - \\
\hline (d) $373.1-377.1$ & unlinked $b_{\alpha}$ & $\mathrm{b}_{\alpha} 3 \rightarrow \operatorname{Biot}\left(\mathrm{O}_{2}\right)-\mathrm{GG}$ & - \\
\hline (s) 405.17 & unlinked $y_{\beta}$ & - & $y_{\beta} 3 \rightarrow D D R$ \\
\hline (d) $430.1-436.1$ & unlinked $b_{\alpha}$ & $\mathrm{b}_{\alpha} 4 \rightarrow \operatorname{Biot}\left(\mathrm{O}_{2}\right)-\mathrm{GGG}$ & - \\
\hline (s) 476.27 & unlinked $y_{\beta}$ & - & $y_{\beta} 4 \rightarrow A D D R$ \\
\hline (d) $487.2-495.2$ & unlinked $b_{\alpha}$ & $\mathrm{b}_{\alpha} 5 \rightarrow \operatorname{Biot}\left(\mathrm{O}_{2}\right)-\mathrm{GGGG}$ & - \\
\hline (d) $544.2-564.2$ & unlinked $b_{\alpha}$ & $\mathrm{b}_{\alpha} 6 \rightarrow \operatorname{Biot}\left(\mathrm{O}_{2}\right)-\mathrm{GGGGG}$ & - \\
\hline (s) 561.50 & unlinked $a_{\beta}$ & - & $a_{\beta} 4 \rightarrow A C C H$ \\
\hline (s) 636.40 & unlinked $y_{\beta}$ & - & $y_{\beta} 5 \rightarrow$ CADDR \\
\hline (s) 761.23 & unlinked $b_{\beta}$ & - & $\mathrm{b}_{\beta} 6 \rightarrow \mathrm{ECCHGD}$ \\
\hline (s) 765.28 & unlinked $y_{\beta}$ & - & $y_{\beta} 6 \rightarrow E C A D D R$ \\
\hline
\end{tabular}


Table A4 List of the attributed $y$ - and b- fragment ions in the HCD spectra of both light and heavy versions of the $4+$ precursor ion of the photocross-linked peptide at $2803-2813(\mathrm{M}+\mathrm{H})^{+}$. Unlinked ions are either in red (originating from $\beta$ sequence) or in blue (originating from from $\alpha$ sequence). Cystein residues are carbamidomethylcysteine, (s) for singlet and (d) doublet

\begin{tabular}{|c|c|c|c|}
\hline Observed $\mathrm{m} / \mathrm{z}$ & $\begin{array}{c}\text { Fragment ion type } \\
\text { HCD }\end{array}$ & $\begin{array}{c}\alpha \text { sequence } \\
\text { Photo(R/W) })_{9} \text { pept. }(1-8)\end{array}$ & $\begin{array}{c}\beta \text { sequence } \\
\text { BSA peptide } \\
\text { ECCHGDLLECADDR }\end{array}$ \\
\hline (s) 175.12 & unlinked $y_{\beta}$ or $y_{\alpha}$ & $Y_{\alpha} 1 \rightarrow R$ & or $y_{\beta} 1 \rightarrow R$ \\
\hline (s) 259.07 & unlinked $b_{\alpha}$ & $" b_{\alpha} 1 " \rightarrow \operatorname{Biot}\left(O_{2}\right)$ & - \\
\hline (d) $288.10-290.11$ & unlinked $a_{\alpha}$ & $a_{\alpha} 2 \rightarrow \operatorname{Biot}\left(O_{2}\right)-G$ & - \\
\hline (s) 290.15 & unlinked $\mathrm{y}_{\beta}$ & - & $y_{\beta} 2 \rightarrow D R$ \\
\hline (d) $316.10-318.11$ & unlinked $b_{\alpha}$ & $\mathrm{b}_{\alpha} 2 \rightarrow \operatorname{Biot}\left(\mathrm{O}_{2}\right)-\mathrm{G}$ & - \\
\hline (d) $345.1-349.1$ & unlinked $a_{\alpha}$ & $\mathrm{a}_{\alpha} 3 \rightarrow \operatorname{Biot}\left(\mathrm{O}_{2}\right)-\mathrm{GG}$ & - \\
\hline (d) $373.12-377.14$ & unlinked $b_{\alpha}$ & $\mathrm{b}_{\alpha} 3 \rightarrow \operatorname{Biot}\left(\mathrm{O}_{2}\right)-\mathrm{GG}$ & - \\
\hline (s) 405.17 & unlinked $y_{\beta}$ & - & $\mathrm{y}_{\beta} 3 \rightarrow \mathrm{DDR}$ \\
\hline (d) $430.14-436.18$ & unlinked $b_{\alpha}$ & $b_{\alpha} 4 \rightarrow \operatorname{Biot}\left(O_{2}\right)-G G G$ & - \\
\hline (s) 476.21 & unlinked $y_{\beta}$ & - & $y_{\beta} 4 \rightarrow A D D R$ \\
\hline (s) 487.32 & unlinked $b_{\alpha}$ & $\mathrm{b}_{\alpha} 5 \rightarrow \operatorname{Biot}\left(\mathrm{O}_{2}\right)-\mathrm{GGGG}$ & - \\
\hline (s) 636.24 & unlinked $y_{\beta}$ & - & $y_{\beta} 5 \rightarrow C A D D R$ \\
\hline (s) 759.21 & unlinked $b_{\beta}$ & - & $b_{\beta} 6 \rightarrow E C C H G D$ \\
\hline (s) 765.28 & unlinked $y_{\beta}$ & - & $y_{\beta} 6 \rightarrow E C A D D R$ \\
\hline (s) 872.30 & unlinked $b_{\beta}$ & - & $\mathrm{b}_{\beta} 7 \rightarrow \mathrm{ECCHGDL}$ \\
\hline
\end{tabular}


Scheme A1 Three commonly used photocross-linking groups benzophenone (Bp), Phenyl azide ( $\mathrm{Pa})$ and Trifluoromethyl phenyl diazirine (TFMFD). Schematics of the stable precursors structures are shown on the left of the first column whereas the highly reactive intermediates, obtained after UV irradiation are shown on the right. The reactivity is mentioned in the right column. Note that formation of the biradical of the benzophenone is reversible

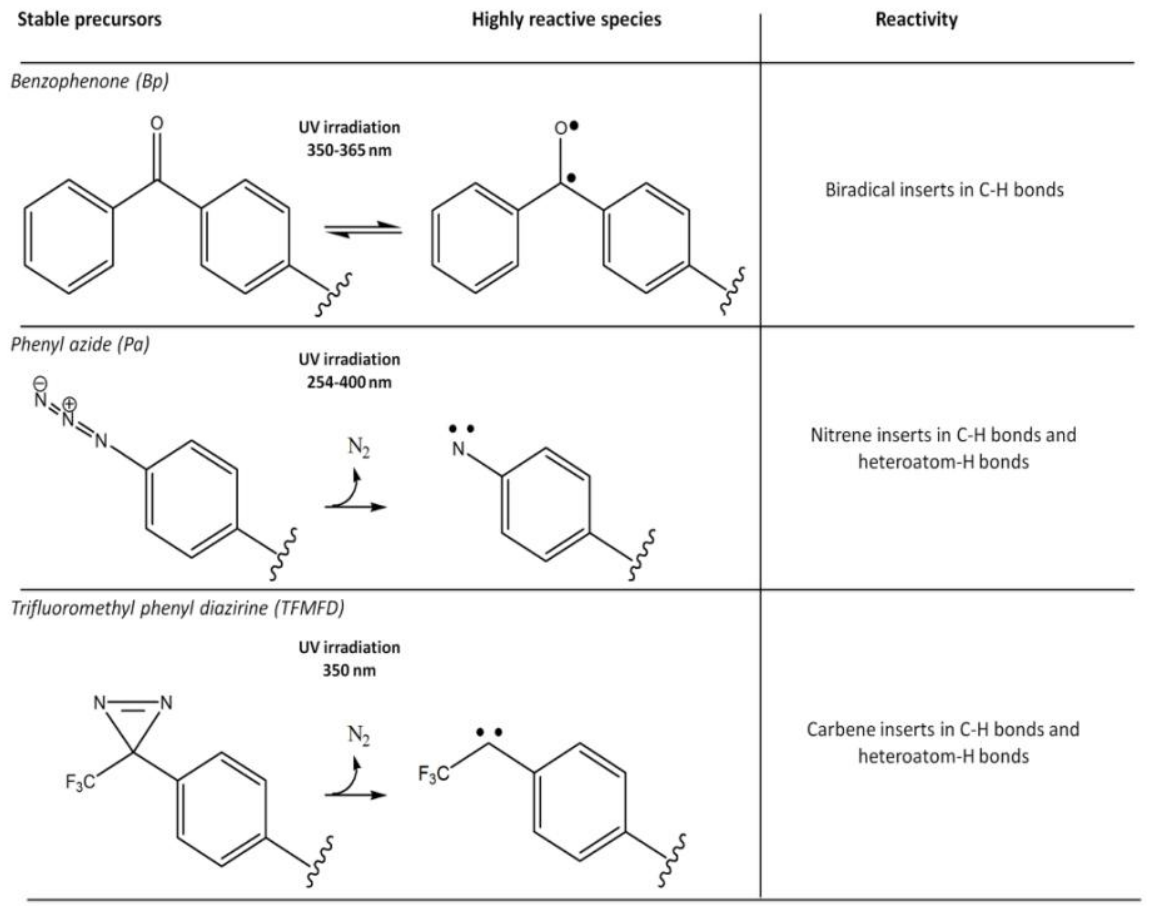


Legends for figures and scheme

Fig. 1 Schematic of the photocross-linking reaction between photo(R/W $)_{9}$ (squared in red) and a protein or peptide partner (e.g. BSA) (colored in blue), using benzophenone (Bp) as the photoprobe. The $\mathrm{Bp}$ is located on the Lys side chain of photo(R/W). Under UV irradiation at $365 \mathrm{~nm}$, the carbonyl group of the $\mathrm{Bp}$ is excited to give a biradical $\mathrm{C}=\mathrm{O}-->\mathrm{C}^{\bullet}-\mathrm{O}^{\bullet}$ extremely reactive towards $\mathrm{C}-\mathrm{H}$ or heteroatom-H bonds (triplet state) of the protein/peptide partner. After hydrogen abstraction and radicals recombination, a covalent bond is formed between photo $(\mathrm{R} / \mathrm{W})_{9}$ and its protein partner (BSA). The covalent complex is labelled in purple.

Fig. 2 a) MALDI-TOF spectrum ( $\mathrm{m} / \mathrm{z}$ range $1000-3000$ ) in positive ions reflector mode of the photocross-linking mixture obtained with $B S A$ and photo $(\mathrm{R} / \mathrm{W})_{9}\left({ }^{1} \mathrm{H} /{ }^{2} \mathrm{H}\right)$ in 1:1 ratio, after trypsin digestion and affinity purification (streptavidin/biotin). CHCA was used as the matrix. In all figures, the color code is the following: blue for the photo(R/W $)_{9}$ trypsic peptide, red for the BSA trypsic peptide and purple for the covalent complexes between photo(R/W $)_{9}$ and $B S A$; b) Schematic representation of the photocross-linked monoprotonated peptide $[\mathrm{M}+\mathrm{H}]^{+}$ion at $\mathrm{m} / \mathrm{z} 2803-2813$. The trypsic peptide photo(R/W) ${ }_{9}$ pept(1-8) (blue) and named $\alpha$ sequence whereas the BSA trypsic peptide is named $\beta$ sequence (red). All the enriched photocross-linked ions appear as doublets with the same intensity separated by $10 / z$ u. (mass units). Most ions produced with the MALDI ions source are monoprotonated +1 . The representative $[\mathrm{M}+\mathrm{H}]^{+}$ion at $\mathrm{m} / \mathrm{z} 2803-2813$ is squared in black and appears as +1 and +2 ions. Photocross-linked ions are labeled in purple and the unreacted photo $(\mathrm{R} / \mathrm{W})_{9} \operatorname{pept}(1-8)$ is labeled in blue

Fig. 3 Chosen nomenclature for the possible sites of CID/ETD fragmentation of the photocross-linked peptides. b, c- and y, z- refer to the classical b-, c- and y- z- ions in CID and ETD fragmentation, $\alpha$ and $\beta$ refer to the CPP (photo $\left.(\mathrm{R} / \mathrm{W})_{9} \operatorname{pept}(1-8)\right)$ (blue) and BSA sequences (red), respectively 
Fig. 4 a) MALDI-TOF/TOF fragmentation of the doublet ion at 2803-2813 corresponding to the photocross-linked peptide photo(R/W) $)_{9}$ pept(1-8) ( $\alpha$ sequence in blue) covalently linked to the BSA trypsic peptide ${ }^{267}$ ECCHGDLLECADDR $^{280}$ ( $\beta$ sequence in red) using a selection window centered at $\mathrm{m} / \mathrm{z}$ 2809 with $R=30$. (s) stands for singlet, (d) for doublet. b) Representation of one of the possible structure for the precursor ion sequence with the covalent bond on the $C \delta$ of the second Leu274 residue of the BSA sequence. Unlinked fragment ions are localized in the $\alpha$ and $\beta$ sequences using vertical bars and labeled in red when the fragmentation is localized in the $\beta$ sequence and in blue when it is on the $\alpha$ sequence. Interlinked fragments are labeled in purple. C-C bond fragments are observed. The fragment ion at $\mathrm{m} / \mathrm{z}$ 1054-1064 corresponds to the photo(R/W) $)_{9}$ peptide (1-8) arising from the fragmentation of the $\mathrm{C}-\mathrm{C}$ bond created by the photocross-linking reaction

Fig. 5 a) ETD spectrum of the light version of the photocross-linked peptide obtained from the 4+ precursor ion ${ }^{* *}$ at $\mathrm{m} / \mathrm{z} 701.76$ (second isotope chosen for MS/MS); b) ETD spectrum of the heavy version of the photocross-linked peptide obtained from the $4+$ precursor ion $* *$ at $\mathrm{m} / \mathrm{z} 704.28$ (second isotope chosen for MS/MS). Ions labelled with * correspond to the unreacted precursor ions, the charge-reduced precursors and their neutral losses. Unlinked c- and z-fragments observed in the light and heavy fragmentation spectra are colored in red since they are generated from the $\beta$ sequence only. Interlinked c- and z- fragment ions observed in the light and heavy fragmentation spectra with a delta mass corresponding to the isotopic label present on the CPP sequence are colored in purple; c) Zoom on the MS2 region of $c \beta 12$ and $z \beta 13$ doubly charged interlinked ions showing a $\Delta \mathrm{m}=5.03 \mathrm{u}$ between the light and the heavy versions; d) Representation of the photocross-linked peptide corresponding to the photo(R/W) $)_{9} \operatorname{pept}(1-8)$ ( $\alpha$ sequence) bond to the BSA sequence ${ }^{267}{ }^{E C C H G D L L E C A D D R}{ }^{280}$ on the Leu274 ( $\beta$ sequence). c- and $z$ - unlinked and interlinked ions are represented as vertical bars. c- and z- interlinked ions are labeled in purple, c- and zunlinked ions from the $\beta$ sequence are labeled in red 
Fig. 6 Proposed strategy to identify photocross-linked peptides and restrict the number of residues potentially involved in the photocross-linking reaction

Scheme I a) Proposed mechanisms for carbamidomethylcystein side chain loss in ETD and b) Leucine side chain loss in ETD. For carbamidomethylcystein side chain loss, abstraction of the $\alpha$ hydrogen yields the observed loss of $90 \mathrm{u}$ (mass units) For Leu side chain loss, abstraction of the $\gamma$ hydrogen yields to the observed loss of $56 \mathrm{u}$ 
Illustrations

Fig.1

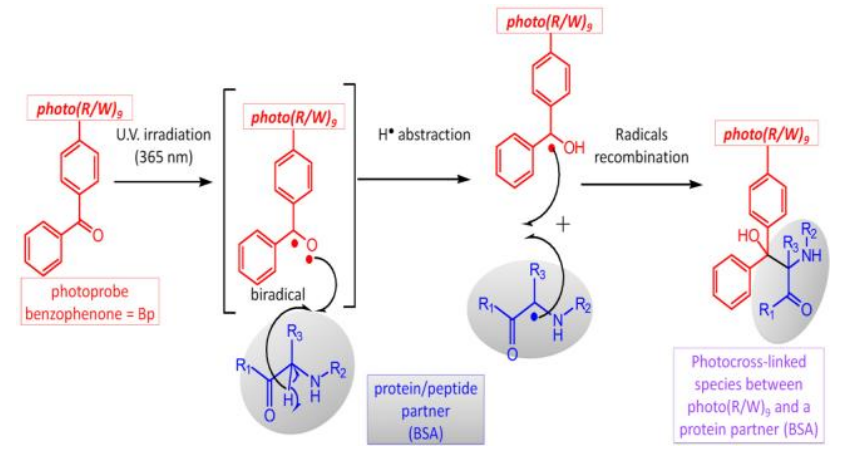

Fig. 2

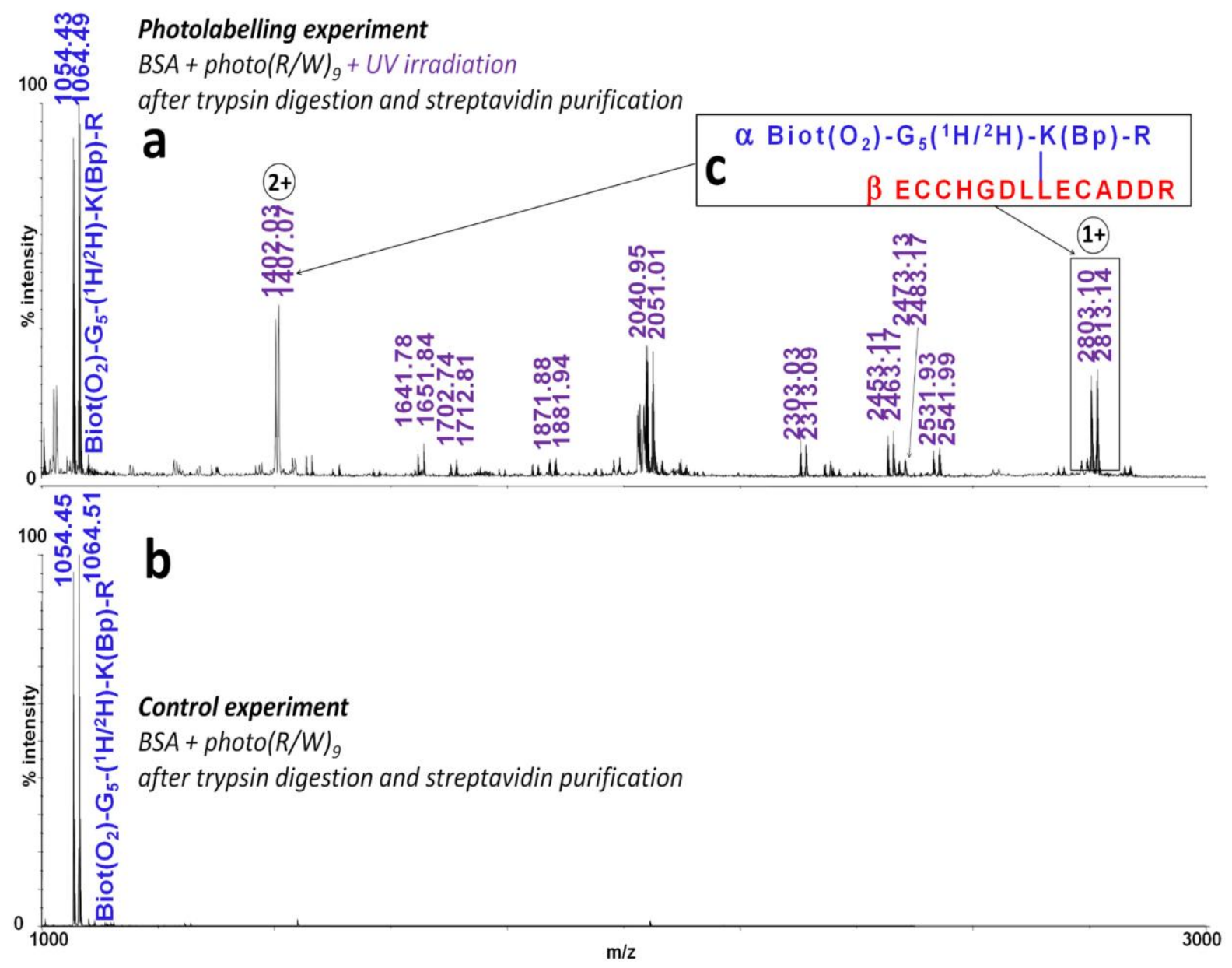


Fig. 3

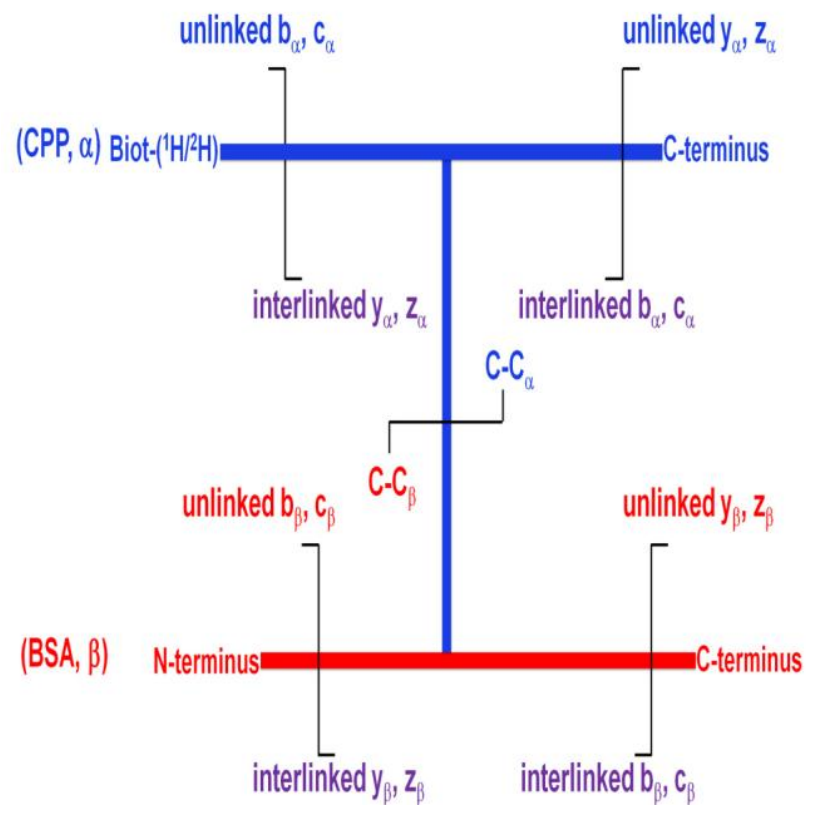


Fig. 4

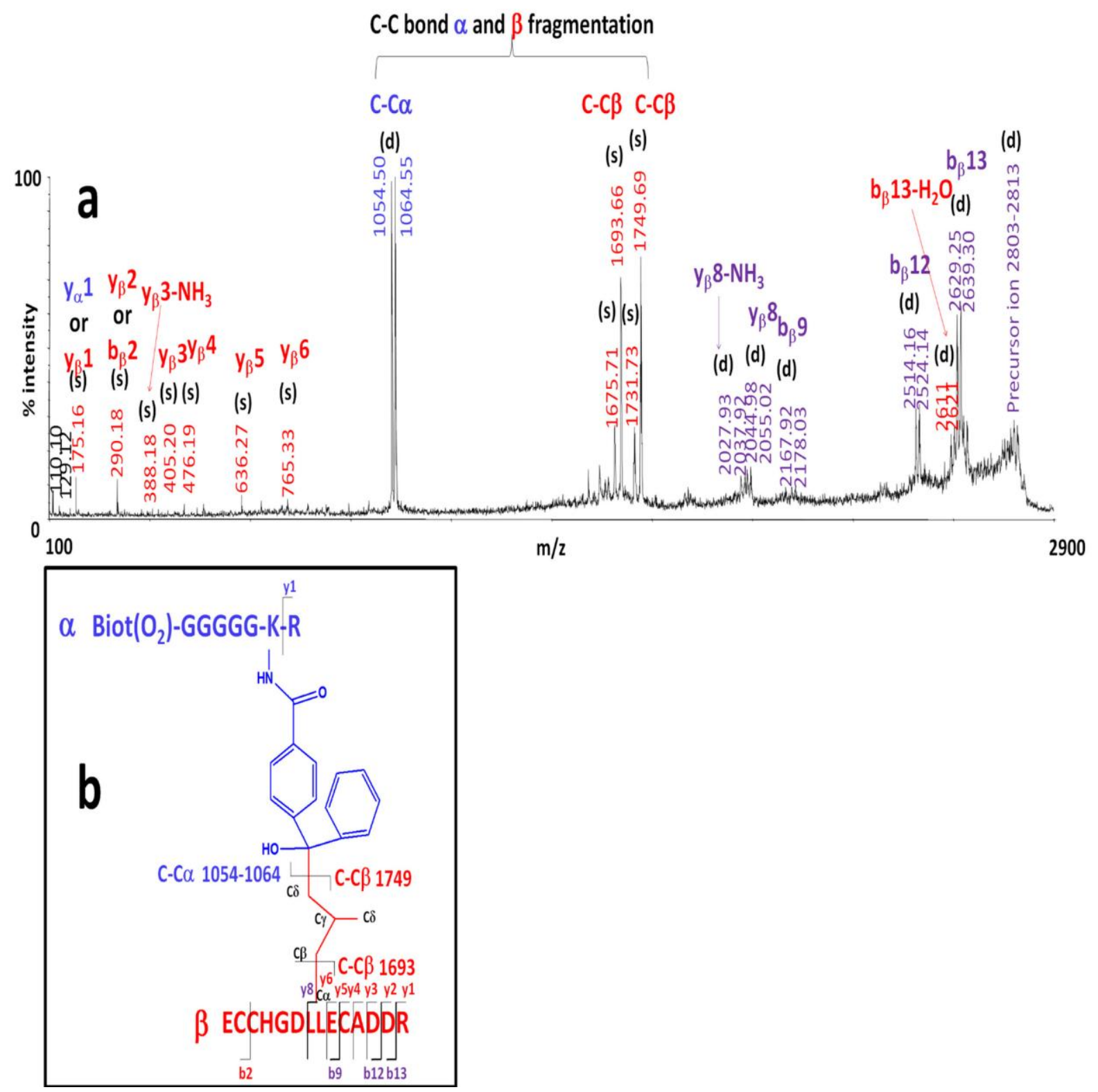


Fig. 5
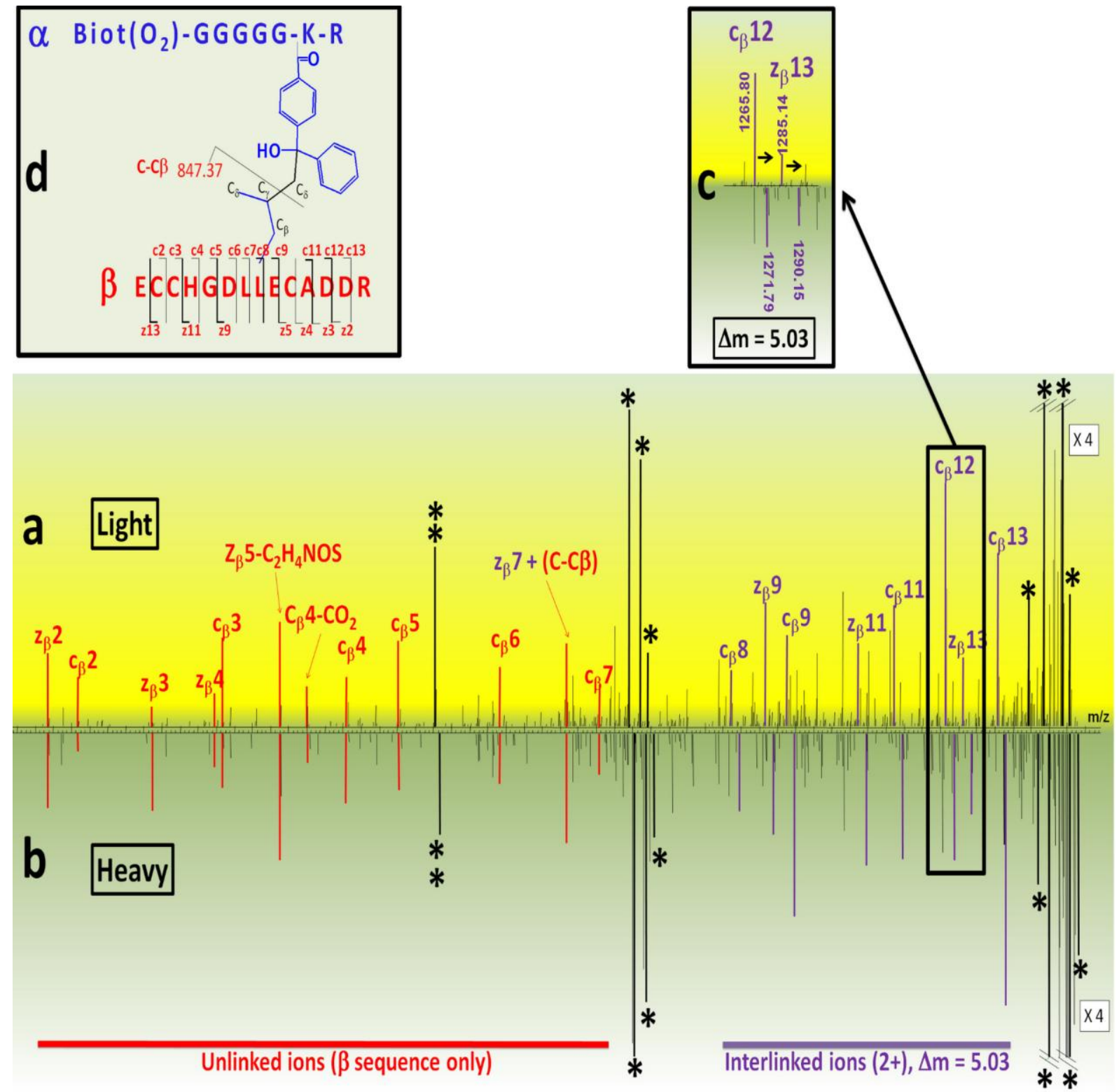
Fig. 6

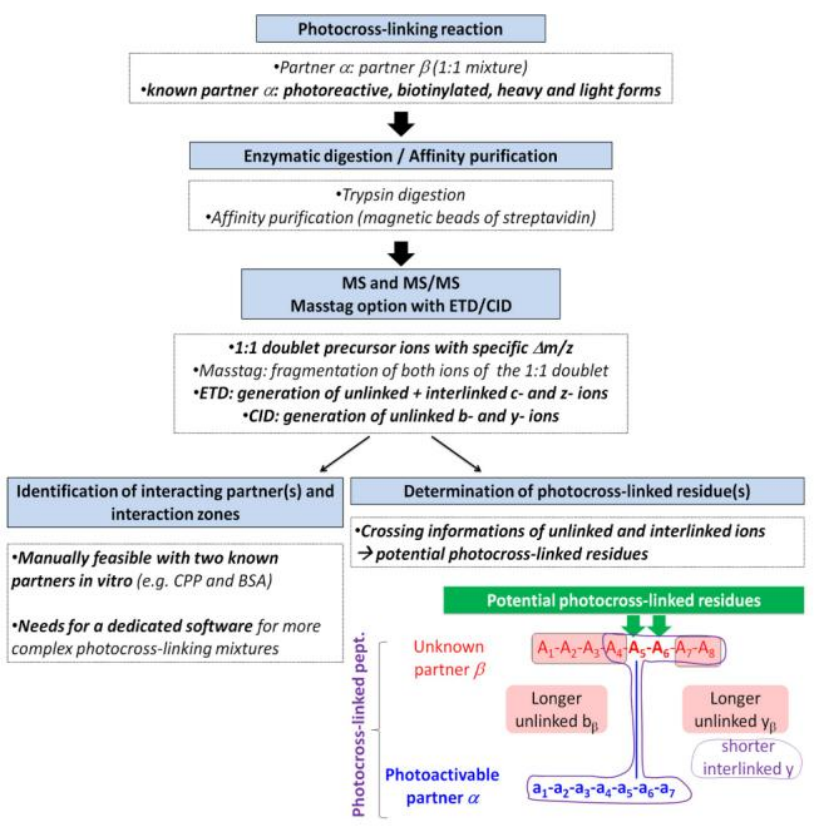

\section{Scheme I}

a

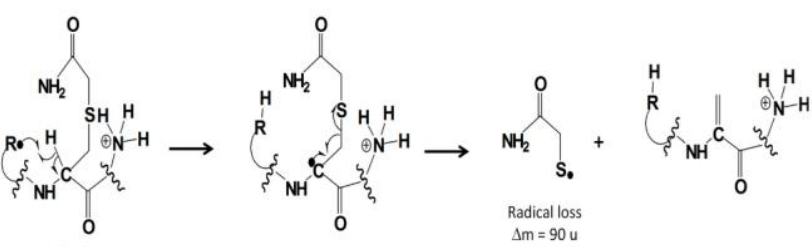

Radical cation

containing a

carbamidomethylcys

b

containing a leu residue 